\title{
LA CANDIDATURA SILENCIOSA \\ LA CAMPAÑA PRESIDENCIAL DEL GENERAL PABLO GONZÁLEZ GARZA EN LAS ELECCIONES DE 1920. UNA MIRADA DESDE LA PRENSA
}

\author{
THE SILENT CAMPAIGN \\ GENERAL PABLO GONZÁLEZ GARZA IN THE PRESIDENTIAL \\ ELECTIONS OF 1920. A LOOK FROM THE PRESS
}

\author{
Francisco Iván MÉndez LARA \\ Universidad Nacional Autónoma de México \\ Posgrado en Historia \\ ivan.mendez.lara@gmail.com
}

\section{Resumen}

El presente artículo analiza a través de fuentes hemerográficas el papel que desempeñó en la sucesión presidencial de 1920 uno de los generales más importantes de la revolución mexicana, Pablo González Garza. Dicho militar era uno de los candidatos naturales - junto con Álvaro Obregón- para suceder a Venustiano Carranza debido al ascendente político que había ganado durante la lucha armada. Al iniciar su campaña optó por una actitud legalista, pero silenciosa y parsimoniosa. Posteriormente, debido al apoyo que Carranza ofreció el ingeniero Ignacio Bonillas para que ocupara la silla más codiciada del país optó por pactar con Obregón y ocupar la capital del país en mayo de 1920 aunque finalmente renunció a su candidatura debido a la imposibilidad de triunfar. Mediante el uso de fuentes poco examinadas, como los periódicos El Heraldo de México, El Monitor Republicano y México Nuevo, se analizan la campaña, la plataforma (la Liga Democrática) y la postura de la prensa gonzalista en dicha coyuntura electoral, temas hasta ahora poco estudiados, incluso olvidados, debido al triunfo del Grupo Sonora.

Palabras clave: Revolución mexicana, elecciones, prensa, Pablo González, Álvaro Obregón.

Abstract

This article analyzes the role played in the 1920 presidential succession by one of the most important generals of the Mexican Revolution, Pablo González Garza. This military man was one of the natural candidates - along with Álvaro Obregón - to succeed Venustiano Carranza due to the political ascendancy he had won during the armed struggle. At the beginning of his campaign he opted for a legalistic attitude, but silent and parsimonious. Later, due to the support that Carranza offered the engineer Ignacio Bonillas to occupy the most coveted chair in the nation, opted to agree with Obregon and occupy the capital of the country in May 1920 but finally resigned his candidacy due to the impossibility of success. Through the use of little-examined sources, such as the newspaper El Heraldo de México, El Monitor Republicano and México Nuevo, are analyzed the campaign, the platform (Liga Democrática) and the position of the gonzalista press in the electoral conjuncture, issues that have not been studied until now, even forgotten, due to the triumph of Grupo Sonora.

Keywords: Mexican Revolution, elections, press, Pablo González, Álvaro Obregón.

Información del artículo

Recibido: 30 de abril de 2019.

Aceptado: 24 de junio 2019.

DOI: $10.22201 /$ iih.24485004e.2019.57.69507 


\section{Introducción}

A finales de junio de 1920 el general Pablo González Garza se trasladó a Estados Unidos para vivir sus últimas décadas de vida, apenas meses atrás era uno de los principales contendientes para ocupar la silla presidencial. ¿Por qué no fue presidente de México?, ¿cuáles fueron sus propuestas y bases políticas?

De entre todos los revolucionarios que participaron en la lucha armada de 1910 a 1920 - Pancho Villa, Emiliano Zapata, Francisco I. Madero, Venustiano Carranza, Álvaro Obregón, Salvador Alvarado y Plutarco Elías Calles, sólo por mencionar algunos-, a Pablo González se le ha prestado poca atención. La historiografía ha relegado su papel a un segundo plano, casi siempre debido a su supuesta "incapacidad" militar y a su "nulo carisma" frente a otros generales de mayor popularidad.

González nació en Lampazos, Nuevo León, el 5 de mayo de 1879, y entre los tres y los cinco años quedó huérfano, por lo que fue criado por sus hermanos mayores, quienes se quedaron al mando de la tienda familiar que había fundado su padre. Estudió la primaria en su lugar de origen y en 1892, debido a su buen desempeño, consiguió una beca para ingresar al Colegio Militar, aunque esto finalmente no se concretó por razones desconocidas. Posteriormente trabajó como minero en Nadadores, Coahuila, y en el molino del Carmen, propiedad de Federico Miller.

Más tarde se mudó a Chihuahua, lugar en donde aprendió el oficio de obrero de la industria metalúrgica y, casi al iniciar el nuevo siglo buscó nuevos horizontes; se trasladó a Estados Unidos para "picar piedra" en múltiples actividades. Junto a su primo Antonio I. Villarreal distribuyó propaganda magonista entre los trabajadores y apoyó económicamente por breve tiempo al movimiento liderado por los hermanos Flores Magón. De vuelta en México se hizo cargo del molino de su exjefe, Federico Miller, con cuya hija contrajo matrimonio.

Al poco tiempo, Jesús Carranza Garza y Cesáreo Castro lo invitaron a apoyar la campaña de Venustiano Carranza Garza, quien competiría por la gubernatura de Coahuila; esta situación lo acercó brevemente al reyismo y meses después a unirse al antirreeleccionismo. Su maderismo quedó claro en enero de 1911 cuando se levantó contra el gobierno de Porfirio Díaz en el Molino del Carmen con sesenta hombres. Tras firmarse los acuerdos de Ciudad Juárez se retiró a la vida privada, pero poco después fue designado jefe de armas en Monclova por Carranza. Más tarde, apoyó la lucha contra 
el general Pascual Orozco al frente del primer regimiento de los Carabineros de Coahuila. ${ }^{1}$

Desde febrero de 1913 fue un fiel seguidor de Carranza -al que secundó al apoyar el Plan de Guadalupe del 26 de marzo de 1913-, quien lo nombró jefe del Ejército del Noreste en julio del mismo año. Pese a ser derrotado por el ejército federal en diversas batallas que llevaron los constitucionalistas a perder el control de Coahuila, meses después reorganizó sus fuerzas, recuperó el control del noreste y bajó, vía Querétaro, hacia la ciudad de México. Para mediados de julio de 1914 se convirtió en uno de los tres militares más importantes, junto con Obregón y Villa, que ayudaron a derrotar a Huerta. En la lucha de facciones operó nuevamente en el noreste, pero también en el oriente y en el centro del país. En agosto de 1915 ocupó la ciudad de México, que se encontraba en manos de los convencionistas, y en mayo del siguiente año el Primer Jefe lo nombró jefe de la campaña contra los zapatistas, labor que suspendió sólo por algunos meses para combatir a los villistas en Chihuahua.

A finales de 1916, mientras se designaban las credenciales en el Congreso Constituyente, González postuló a Carranza como candidato presidencial, y entre el 23 y el 25 de octubre diversos militares se reunieron en la casa del propio González para acordar los puntos básicos del que habría de ser el partido conformado por los revolucionarios triunfantes, el cual llevaría al primer jefe a convertirse en la cabeza del Ejecutivo federal: el Liberal Constitucionalista. ${ }^{2}$ No obstante, debido a diferencias irreconciliables con el grupo que quedó al frente del partido, que comenzaba a mostrar cierto favoritismo por Obregón, lo abandonó apenas en la primera quincena de enero de $1918 .^{3}$

Un mes después de la ruptura con el Partido Liberal Constitucionalista fue designado jefe de Operaciones Militares del Sur (que incluía el estado de Guerrero); retomó sus labores en Morelos y organizó, junto con el general Jesús Guajardo, un plan que concluyó con el asesinato de Emiliano Zapata el 10 de abril de 1919 en la hacienda de Chinameca, Morelos. Una vez consumado el

${ }^{1}$ Pedro Salmerón, Los carrancistas. La historia nunca contada del victorioso Ejército del Noreste, México, Planeta, 2009, p. 90-92; Javier Echeverría A. Marquina, ¡Viva Carranza! Mis recuerdos de la Revolución, México, Marvel, 1963, p. 145-163.

${ }^{2}$ Juan Barragán Rodríguez, Historia del Ejército y de la Revolución Constitucionalista, México, Instituto Nacional de Estudios Históricos de la Revolución Mexicana, 1986, v. III, p. 319; Bertha Ulloa, La Constitución de 1917, México, El Colegio de México, 1983 (Col. Historia de la Revolución Mexicana, 6), p. 502-503.

${ }^{3}$ El Pueblo, 13 de enero de 1918, p. 1. 
asesinato del caudillo del sur, combatió diversos brotes felicistas en Puebla y Oaxaca, pero pronto regresó a la ciudad de México en donde esperó pacientemente para iniciar su campaña rumbo a la presidencia. ${ }^{4}$

La mayoría de los historiadores ha menospreciado la figura de González. Contados casos muestran una visión más equilibrada de este personaje. ${ }^{5}$ Su liderazgo sobre una fracción del ejército lo colocó como uno de los candidatos naturales para suceder a Carranza en la presidencia de la república. No obstante, su carrera política ha sido escasamente estudiada y eclipsada por la de Obregón, con quien ascendió a los primeros planos nacionales de forma paralela desde 1913. Dicha situación en términos explicativos resulta entendible ya que el triunfo del general invicto significó la llegada al poder de un nuevo sector que tendría el control del país al menos durante los siguientes tres lustros, el Grupo Sonora. ${ }^{6}$

${ }^{4}$ Diccionario de generales de la Revolución, México, Instituto Nacional de Estudios Históricos de las Revoluciones de México/Secretaría de la Defensa Nacional/Secretaría de Educación Pública, 2014, v. I, p. 439-442.

${ }^{5}$ Uno de los generales más cercanos al neoleonés, Manuel W. González, escribió un libro intitulado Con Carranza, en el que explicó con mayor detalle algunas acciones del divisionario, pero al mismo tiempo mostró una visión parcial del personaje al exaltar sus acciones en la lucha armada. Asimismo, el español Vicente Blasco Ibáñez retrató a González como un hombre que no despertaba gran interés al carecer de carisma, ya que en gran medida había "permanecido en segundo término, como obscurecido por la vida exuberante y la popularidad agresiva de Obregón”, Vicente Blasco Ibáñez, El militarismo mejicano. Estudios publicados en los principales diarios de los Estados Unidos, Valencia, Prometeo, 1920, p. 104. En el ámbito académico Pedro Salmerón llama la atención sobre este menosprecio hacia el personaje principalmente en el contexto de la lucha contra Huerta (Los carrancistas..., p. 86-90). Por su parte, Javier Garciadiego descarta su incapacidad militar y analiza las derrotas de 1913, que llevó al movimiento constitucionalista a perder Coahuila frente al ejército federal, como algo que no podía evitarse. Javier Garciadiego, "La prensa durante la Revolución Mexicana", en Aurora Cano Andaluz (coord.), Las publicaciones periódicas y la historia de México, México, Universidad Nacional Autónoma de México, 1995, p. 71-88; y del mismo autor "Pablo González y las dificultades en el noreste" y "Los éxitos de Pablo González”, en Así fue la Revolución Mexicana, 9 v., México, Comisión Nacional para la Celebración del 175 Aniversario de la Independencia Nacional y 75 Aniversario de la Revolución Mexicana, Senado de la República/Secretaría de Educación Pública, Instituto Nacional de Antropología e Historia/Consejo Nacional de Fomento Educativo, Dirección General de Publicaciones y Medios, 1985, v. 4, p. 559-555, 661-665.

${ }^{6}$ Pese a ser llamado de esta forma es importante mencionar que no todos eran oriundos de dicho estado, basta mencionar como ejemplo a los generales Benjamín G. Hill y Francisco R. Serrano, nacidos en Sinaloa, o a personajes de segundo nivel dentro de la agrupación como el general Eugenio Martínez, quien era zacatecano, o el propio Lázaro Cárdenas del Río, nacido en Michoacán. Se trataba de una agrupación regional que tuvo su génesis en la lucha contra la rebelión orozquista en 1912 y con el pasar de los años se expandió debido 
Este artículo estudia la campaña de González en busca de la presidencia de la república entre 1919 y 1920 con base en el análisis de fuentes hemerográficas poco exploradas como El Heraldo de México, El Monitor Republicano y México Nuevo. Además se echa mano de otras fuentes primarias y diversos diarios como El Pueblo, El Universal, Excélsior y El Demócrata.

Es importante mencionar que al iniciar la coyuntura electoral los órganos informativos más importantes de la ciudad de México eran El Universal, Excélsior, El Pueblo -desapareció pronto, el 15 de mayo de 1919- y El Demócrata. El gobierno manejaba El Demócrata y El Pueblo, el primero lo controlaba el secretario de Gobernación, licenciado Manuel Aguirre Berlanga; desde 1918 ambos rotativos se inclinaron a la idea de que un civil debía ocupar el Ejecutivo federal. El Universal de Félix F. Palavicini era el diario de mayor tiraje y en un primer momento pareció favorecer a González, pero paulatinamente optó por una tendencia neutral que dejó de lado en mayo de 1920 cuando apoyó el triunfo sonorense. Excélsior, cuyo propietario era Rafael Alducin, era el segundo diario más importante y fue el principal impulsor de la postura "civilista" para atacar a los militares en sus campañas de propaganda. ${ }^{7}$

En 1919 se fundaron tres periódicos electoreros: El Heraldo de México, México Nuevo y El Monitor Republicano. El primero fue creado en abril de dicho año por el general Salvador Alvarado en un intento por competir por la presidencia. Ese proyecto fracasó y terminó por apoyar al Grupo Sonora. Por otro lado, en julio del año mencionado apareció El Monitor Republicano, órgano de propaganda del Partido Liberal Constitucionalista que difundió las propuestas de Obregón y se enfrentó a una importante censura por parte del gobierno carrancista, principalmente desde febrero de 1920. Como director estuvo Basilio Vadillo y sus colaboradores fueron los miembros de la propia agrupación política, entre los que destacaron Miguel Ángel Peralta, Luis L. León y dos exiliados —el general Antonio I. Villarreal y José Vasconcelos- que vieron en el diario la posibilidad de volver al país tras apoyar con sus artículos, redactados desde Estados Unidos, al "héroe de Celaya”. Finalmente, México Nuevo, uno de los temas de este artículo, fue creado hacia finales de 1919 y apoyó la candidatura de González. Este diario además de ser de difícil acceso, es una fuente casi ignorada.

a las redes tejidas y a la relevancia política que comenzaron a ganar sus hombres más importantes, los generales Álvaro Obregón y Plutarco Elías Calles, y el extenedor de libros y cantante Adolfo de la Huerta.

7 Álvaro Matute, La carrera del caudillo, México, El Colegio de México, 1980 (Col. Historia de la Revolución Mexicana, 8), p. 20, 22, 24. 
Álvaro Matute realizó el estudio más completo de la coyuntura electoral de 1920, sin ahondar en la campaña de González ni en su propaganda en la prensa, principalmente en México Nuevo. ${ }^{8}$ Por ello múltiples vetas aún pueden ser exploradas y explotadas, entre ellas la propia candidatura del general neoleonés, las propuestas políticas y las bases de apoyo del gonzalismo, además de la constante discusión y confrontación en los principales periódicos del país en torno a su "inexistente campaña" electoral, objetivos primordiales de este artículo.

El presente texto consta de cuatro partes. En la primera se estudian los momentos previos al destape del neoleonés como candidato presidencial, las polémicas con Obregón y las opiniones vertidas en los periódicos sobre esta primera fase electoral. En la segunda se analiza el inicio de su campaña y sus bases de apoyo, particularmente se revisa el programa político de la Liga Democrática y sus miembros. En la tercera se reconstruye con base en México Nuevo la imagen de González durante el periodo de enero-marzo de 1920, meses clave en el desarrollo de su campaña. En la cuarta y última se explican el pacto con Obregón de abril de 1920, la posterior ocupación

${ }^{8}$ Ibidem, p. 29-30, 49-55, 78-80. Existen estudios sobre las campañas y sucesiones presidenciales que han utilizado a la prensa como fuente y, en ocasiones, como objeto de análisis. La de 1920, como se ha señalado, fue estudiada por Matute; la de 1923-1924 que llevó a Plutarco Elías Calles a la presidencia ha sido explicada con precisión por Georgette José ( $\mathrm{La}$ campaña presidencial de 1923-1924 en México, México, Instituto Nacional de Estudios Históricos de la Revolución Mexicana, 1998). Otro trabajo subrayable es el de Silvia González Marín (Prensa y poder político. La elección presidencial de 1940 en la prensa mexicana, México, Siglo XXI/Universidad Nacional Autónoma de México, Instituto de Investigaciones Bibliográficas, 2006), quien estudió la coyuntura electoral de 1939-1940 en la que Ávila Camacho resultó ganador. En años recientes Gantús y Salmerón han publicado y coordinado diversas obras sobre la historia electoral decimonónica y su relación con la prensa, basta mencionar dos ejemplos (Fausta Gantús y Alicia Salmerón (coord.), Prensa y elecciones. Formas de hacer política en el México decimonónico, México, Instituto de Investigaciones Dr. José María Luis Mora, 2014, y Fausta Gantús y Alicia Salmerón (coord.), Cuando las armas hablan, los impresos luchan, la exclusión agrede..., México, Instituto de Investigaciones Dr. José María Luis Mora, 2016). Un balance general de la prensa revolucionaria en Garciadiego ("La prensa durante la Revolución...”). Asimismo existen otros textos más particulares como los de Ana María Serna Rodríguez, "Periodismo, Estado y opinión pública en los inicios de los años veinte (19191924)”, Secuencia, n. 68, 2007, p. 57-85, y "Prensa y sociedad en las décadas revolucionarias (1910-1940)", Secuencia, n. 86, 2014, p. 111-149; y Arno Burkholder de la Rosa, "El periódico que llegó a la vida nacional. Los primeros años del diario Excélsior (1916-1932)”, Historia Mexicana, El Colegio de México, Centro de Estudios Históricos, México, v. LviII, n. 232, abril-junio 2009, p. 1369-1418. Uno de los libros que analiza con detalle un periódico revolucionario es el de Ricardo Cruz García, Nueva Era y la prensa en el maderismo, México, Universidad Nacional Autónoma de México, Instituto de Investigaciones Históricas, 2013. 
de la ciudad de México por las fuerzas gonzalinas en mayo del mismo año y finalmente la renuncia a su candidatura.

Como lo ha señalado una autora, la realización de las elecciones presidenciales suele representar el periodo de "mayor vulnerabilidad política" ya que durante el desarrollo de las campañas "emergen todas las debilidades y fortalezas del régimen imperante, y las pugnas soterradas y durante algún tiempo contenidas entre los factores reales de poder, sobre todo los económicos y los políticos, salen a la luz y se enfrentan de manera pacífica o violenta". ${ }^{9}$ De ahí la relevancia y necesidad de ser estudiadas y reinterpretadas.

\section{El inicio de la contienda}

A mediados de enero de 1919, el presidente constitucional Venustiano Carranza publicó un documento en el que pedía a los posibles aspirantes a la presidencia que esperaran algunos meses antes de dar inicio a sus campañas de propaganda para, de esa forma, no alterar el orden que se había conseguido después de un periodo de constantes luchas de todo tipo. Tal y como lo pidió Carranza, los presidenciables aguardaron varios meses antes de destapar sus candidaturas. El primero que tomó la pluma para colocarse como candidato fue Obregón, el militar invicto de la lucha armada y quien se perfilaba como el hombre favorito para suceder a Carranza debido a su carisma y popularidad. Su interés por ocupar la presidencia era un secreto a voces desde años atrás, pese a afirmar en mayo de 1917 -tras abandonar la Secretaría de Guerra y Marina-que se alejaría de la política para cuidar su salud y se retiraría a la vida privada para impulsar su empresa garbancera.

El 1o. de junio del mismo año, Obregón dio a conocer el manifiesto "de la resaca” en el que señalaba que el viejo Partido Liberal se encontraba en una situación "desastrosa" debido a que el régimen carrancista no había sido capaz de depurar al ejército, principal problema "moral" que aquejaba a México. Entre todas las dificultades políticas, la principal y más importante era la inexistencia del sufragio libre; una vez zancado éste se podría iniciar la reconstrucción del país. El manifiesto cuestionaba la práctica de

${ }^{9}$ José Valenzuela, "La rebelión delahuertista: sus orígenes y consecuencias políticas, económicas y sociales”, en Javier Garciadiego (coord.), El Ejército Mexicano. 100 años de historia, México, El Colegio de México, 2014, p. 213-270, p. 213. 
los presidentes que estaban por terminar su cuatrienio, que se enfocaban en crear un sucesor "capacitado para concluir su obra", un mensaje evidentemente dirigido al presidente para que no interviniera en la definición de las elecciones del siguiente año. ${ }^{10}$ Debido a la escisión en el seno de los revolucionarios, Obregón no aceptaba el apoyo de ningún partido; en cambio, llamaba a reorganizar el Gran Partido Liberal del que se asumía candidato. Finalmente, concluía con un llamado a los ciudadanos para que organizaran clubes políticos de apoyo a sus propuestas. Pese a afirmar tal cosa, el Partido Liberal Constitucionalista se convirtió en la base política del sonorense al menos durante la primera fase de la contienda electoral.

Semanas después, el 23 de junio, la primera plana de El Universal publicó las declaraciones de Pablo González respecto del manifiesto. El divisionario criticó el procedimiento personalista y "retrógrado" de Obregón, a cuyo texto adjetivó como una simple "prosa rimada" que sólo se encargaría de "obstruccionar" a la naciente democracia mexicana por la que tanto se había luchado en los últimos años. ${ }^{11}$ Más adelante, González citaba los ejemplos de personajes como los expresidentes Porfirio Díaz y Victoriano Huerta, y el daño hecho al país sobre todo si se utilizaban esos métodos para una campaña presidencial. En pocas palabras, González se mostró completamente en contra del inicio de la campaña obregonista. Excélsior aseguró que ambos contendientes eran prácticamente iguales, ya que sólo buscaban alcanzar el poder y los supuestos intereses democráticos de los que tanto hablaban eran en realidad su ambición encubierta. ${ }^{12}$

Días más tarde, y contrario a sus declaraciones, González explicitó en una carta dirigida a Obregón la posibilidad de firmar un pacto en el que se pudiera prevenir el uso de la violencia en el momento en que uno de los dos triunfara. Propuso no injuriar al contrario, no utilizar métodos ilegales para obtener votos y no aprovechar las influencias políticas, militares y administrativas que tenían de su lado. Finalmente, le ofrecía su colaboración en caso de ganar, pero si él era el elegido esperaba la misma respuesta de su parte. ${ }^{13}$

${ }^{10}$ Mario Contreras y Jesús Tamayo (comp.), Antología. México en el siglo XX, 1913-1920. Textos y documentos, México, Universidad Nacional Autónoma de México, Facultad de Filosofía y Letras, 1976, p. 328.

${ }^{11}$ El Universal, 23 de junio de 1919, p. 1.

${ }^{12}$ Excélsior, 26 de junio de 1919, p. 1.

${ }_{13}$ Miguel Alessio Robles, Historia política de la Revolución Mexicana, México, Botas, 1946, p. 89; Matute, La carrera..., p. 49-54; Luis N. Ruvalcaba, Campaña política del [...] candidato a la Presidencia de la República, 1920-1924, México, s. e., 1923, v. I, p. 104-107. 
En ese momento dio a conocer abiertamente su intención de competir por la presidencia de la república. Poco menos de un mes después, los obregonistas, a través de El Monitor Republicano, criticaron la manera en que González se postuló a la presidencia, pues contradecía lo afirmado en la entrevista que había ofrecido a El Universal semanas antes. ${ }^{14}$

La estrategia de González fue ideal para que Obregón criticara sus métodos y, de paso, se mostrara como un defensor de la libertad de sufragio. El general invicto afirmó que la carta "campeaba indudablemente una buena intención”, pero era imposible aceptar la propuesta porque hería el espíritu democrático de los partidos y agrupaciones políticas que los respaldaban, así como a México en general. De llevarse a cabo el planteamiento, significaría que los destinos del país estarían guiados solamente por "el capricho" de ambos. ${ }^{15}$

La polémica periodística no se hizo esperar e incluso se especuló que Obregón y Carranza tenían un acuerdo previo para alternarse en la presidencia. González respondió que lamentaba el rechazo de sus "patrióticas proposiciones" con base en "extraños juicios y encubiertas amenazas". Le pedía el neoleonés al general que publicara cuanto antes los documentos en donde manchaban su "honorabilidad", que tanto había anunciado y que esperaba en vano. ${ }^{16}$

Obregonistas y gonzalistas se enfrascaron en una lucha que parecía favorecer la llegada a la presidencia de un civil y no un militar en 1920, tal y como Carranza lo buscaba. Dicha confrontación, entre el civilismo y el militarismo, como lo planteó Matute, fue innegable durante la coyuntura electoral; no obstante resumir ésta sólo a partir de dicho conflicto sería simplificarla excesivamente y aceptar la interpretación que le dieron los dos periódicos más importantes Excélsior y El Universal, aunque éste en menor grado. Las alianzas y las rupturas entre estos dos sectores de la sociedad, civiles y militares, fueron tema común durante los siguientes meses.

Otro periódico, El Heraldo de México, cuyo dueño era el general Salvador Alvarado, se mostró en contra del intento de unión de los divisiona-

${ }^{14}$ El Monitor Republicano, 21 de julio de 1919, p. 1.

15 Álvaro Obregón. Carta a Pablo González, Nogales, Sonora, 3 de julio de 1919, en Fideicomiso Archivos Plutarco Elías Calles-Fernando Torreblanca, Fondo Álvaro Obregón, exp. Pablo González, f. 1-2; El Universal, 10 de julio de 1919, p. 1.

${ }^{16}$ Pablo González. Carta a Álvaro Obregón, Puebla, Puebla, 21 de julio de 1919, en Fideicomiso Archivos Plutarco Elías Calles-Fernando Torreblanca, Fondo Álvaro Obregón, exp. Pablo González, f. 5. 
rios. ${ }^{17}$ Incluso se rumoró en sus páginas la existencia de otro pacto al que se había llegado desde 1916 entre González y Carranza para turnarse en la presidencia con Obregón. ${ }^{18}$ En el diario también se aprovechó el momento para realizar un llamado a los dos candidatos para que unificaran el partido revolucionario y renunciaran a sus candidaturas para postular a otros hombres más capacitados. ${ }^{19}$ Era evidente la estrategia del diario, según la cual todos los candidatos se mostraban lejos de la postura democrática que el país necesitaba, la opción indicada era el general Salvador Alvarado, cuyo proyecto de gobierno vertido en su obra La reconstrucción de México era el que el país necesitaba. ${ }^{20}$

Meses después, durante el aniversario del inicio de la independencia de México, en El Monitor Republicano se criticó la postura de González respecto de que estaba más preocupado por encontrar el apoyo de Estados Unidos que el del pueblo mexicano; además se afirmaba en sus líneas que no había solicitado su baja del ejército para competir en los comicios, aunque el rumor de que abandonaría las filas castrenses circulaba en las líneas periodísticas después del asesinato de Zapata. ${ }^{21}$ El periódico peleceano aseguró que, después de haber recibido la negativa de Obregón para pactar y turnarse la presidencia, el nacido en Nuevo León había enmudecido y parecía que no continuaría con su campaña. Sin embargo, aquellos que pensaran así estaban equivocados: "Porque el general don Pablo González sigue una tenaz, activísima propaganda, sólo que haciendo gala de un maquiavelismo que nadie podía sospechar, su campaña política no la lleva a cabo en México que, al fin y al cabo ¡qué le importan los votos de sus conciudadanos! sino en la Casa Blanca". ${ }^{22}$ No existen datos para precisar si González realizó un viaje al país vecino del norte por esos días y si buscó su apoyo, al parecer se trató de una estrategia propagandística con el objetivo de vincular al candidato con Estados Unidos en pleno festejo de la independencia de México. No obstante, meses después volvió a mencionarse en la prensa que el neoleonés tenía apoyo de empresarios y hacendados mexicanos y extranjeros, respaldo que no parece descabellado si se

${ }^{17}$ El Heraldo de México, 11 y 12 de julio de 1919, p. 1.

${ }^{18}$ Ibidem, 25 de julio de 1919, p. 1.

${ }^{19}$ Ibidem, 23 de agosto de 1919, p. 3.

${ }^{20}$ Francisco Iván Méndez Lara, "Salvador Alvarado y las elecciones de 1920, una candidatura olvidada”, Secuencia, n. 99, 2017, p. 129-159.

${ }^{21}$ El Pueblo, 24 de abril de 1919, p. 3.

${ }^{22}$ El Monitor Republicano, 15 de septiembre de 1919, p. 1. 
toma en cuenta que para 1922, mientras se le acusaba de iniciar una rebelión contra los sonorenses, se le relacionó con distintos petroleros estadounidenses que supuestamente lo apoyaban desde su campaña electoral. ${ }^{23}$

A lo largo de septiembre y octubre, antes de que González iniciara oficialmente su campaña, en El Monitor Republicano se publicó una serie de juicios negativos con la que, según el diario, el neoleonés arribaba a la contienda electoral. Entre esas opiniones el diario enlistaba su extraordinario enriquecimiento personal por tener bajo su poder algunas de las propiedades que habían pertenecido a los científicos porfiristas, relacionándolo evidentemente con la banda del automóvil gris. Otros de los aspectos que se mencionaron, además de la propuesta de "turnarse" la silla presidencial, fue el asesinato de Zapata con el apoyo del general Jesús Guajardo, señalamiento que significó un duro revés a largo plazo para que llevara a cabo alianzas con los sureños, sumidos en una profunda crisis cuando fue asesinado su caudillo. ${ }^{24}$

Junto a ello, el periódico obregonista criticó, sin prueba alguna, el asesinato de obregonistas en la zona de dominio de las fuerzas gonzalistas sin que éstos recibieran un castigo por sus actos. Por otro lado, destacaron unas supuestas declaraciones de González dadas a conocer en Excélsior según las cuales estaba dispuesto a cerrar las puertas de la Cámara de Diputados como una medida de orden durante los comicios. Esto último llevó a comparar sus posibles actos con los del general Victoriano Huerta en octubre de 1913. ${ }^{25}$ Tomando como base todos los puntos anteriores, se creó la imagen de Pablo González como el candidato conservador, como contraparte de las posturas obregonistas. ${ }^{26}$

Eran golpes certeros contra el candidato; no obstante, la difusión de los puntos enlistados no fue utilizada en muchos editoriales ni notas periodísticas. Parecía que los periódicos guardaban ciertas dudas sobre el papel y

${ }^{23}$ El Universal, 1 de febrero de 1920, p. 1; Excélsior, 7 de febrero de 1922, p. 1.

${ }^{24}$ Francisco Pineda Gómez, La guerra zapatista, 1916-1919, México, Era/Secretaría de Cultura, Instituto Nacional de Antropología e Historia, 2019, p. 328-345. Una vez consumado el asesinato, González felicitó al presidente Carranza por el asesinato del "célebre cabecilla" que había escapado durante años de las fuerzas carrancistas. Asimismo, afirmaba que el cadáver de Zapata había sido identificado y sería fotografiado para que sus seguidores no pudieran dudar de que se trataba de "un hecho efectivo que sucumbió el famoso jefe de la rebelión suriana”, Pablo González a Venustiano Carranza, Cuautla, Morelos, 10 de abril de 1919. El Pueblo, 11 de abril de 1919, p. 1.

${ }^{25}$ El Monitor Republicano, 23 y 24 de octubre de 1919, p. 1.

${ }^{26}$ Ibidem, 26 de octubre de 1919, p. 1. 
los planes que pensaba desempeñar González en la lucha electoral, lo que revela cierto respeto por su ascendente político-militar. Al iniciar noviembre de 1919 poco se sabía de la campaña gonzalina y de su programa de gobierno. La Liga Democrática estaba por nacer.

\section{La plataforma y el periódico, la Liga Democrática y México Nuevo}

Lejos de ser un personaje unidimensional, "gris" o poco carismático, es importante mencionar que González ha sido subestimado. Hasta mediados de 1918 aparecía como el general carrancista con mayores posibilidades de llegar a la presidencia, pues continuamente se le veía al lado de Carranza en los múltiples compromisos que éste tenía. Todavía, en el tercer cuatrimestre de 1918, el neoleonés acompañó al presidente a una gira por el sur del país y el Estado de México para averiguar la mejor forma de solucionar los problemas de la región, viaje del que regresaron en septiembre de 1918. Además todavía al finalizar 1918 el divisionario acudió a eventos sociales íntimos del grupo en el poder, como el bautismo de la hija del secretario de Gobernación, Manuel Aguirre Berlanga. ${ }^{27}$ Es probable que González no contara con que, al iniciar 1919 Carranza impulsara un juego político para intentar hacer a un lado a los militares, enfrentarlos entre sí y poner en la silla presidencial a un incondicional. Sus planes se fueron por la borda.

Más allá de las polémicas y los rumores periodísticos "Don Pablo", como lo llamaban sus subordinados, fue cuidadoso en los pasos a seguir antes de lanzarse a la contienda. Respetó el llamado del presidente de la república para alargar el inicio de las campañas y fue hasta el 8 de noviembre de 1919 cuando solicitó su baja del ejército, petición que Carranza y el Senado aceptaron días más tarde. González creía necesario que su camino hacia la presidencia se efectuara bajo lo establecido en la ley tal vez con el apoyo de su “jefe”. Una vez obtenida la licencia del ejército, González podía ser postulado por una asociación política.

En el fondo, González creía ser el sucesor de Carranza y que eventualmente recibiría su apoyo, pero ello no ocurrió. Don Venustiano optó por una tercera opción, la de un civil de bajo perfil que le había sido leal a lo largo de los años, la del ingeniero agrónomo sonorense Ignacio Bonillas. Hombre desconocido para el grueso del país, pero con dotes administrativos

${ }^{27}$ El Pueblo, 11 de septiembre y 25 de noviembre de 1918, p. 1. 
y diplomáticos - era embajador de México en Washington- que le podían ayudar en caso de arribar a la silla presidencial. Es innegable que Carranza no apoyó al neoleonés con el objetivo de romper con el militarismo imperante y de paso seguir tras el trono con el apoyo de un hombre con poco arraigo en el país, como lo era Bonillas.

Durante la primera semana de noviembre de 1919, en el seno de los círculos políticos se afirmaba que González estaba "sentido" con el presidente "porque según tenía entendido, él iba a ayudar en contra del C. Obregón y como al fin lo ha hecho con Bonillas, piensa que le jugaron una mala partida y su resentimiento es profundo, por más que lo disimule". ${ }^{28} \mathrm{Se}$ llegó a especular que prefería aconsejar a sus partidarios que votaran por Obregón y no por el "candidato oficial".

Finalmente, en diciembre de 1919 se llevó a cabo la Convención de la Liga Democrática, base política del gonzalismo. ${ }^{29}$ En ella se presentaron distintas candidaturas con el fin de darle un toque democrático. Entre los "presidenciables" estuvieron el director gerente de El Universal, Félix F. Palavicini; el embajador y exsecretario de Carranza, Eliseo Arredondo; y Fernando Iglesias Calderón de amplia experiencia revolucionaria desde el maderismo. ${ }^{30}$ El 13 de diciembre en el teatro Arbéu, González tomó protesta de manera oficial como el candidato de la Liga sin el apoyo de Carranza, quien lo felicitó y deseó buena suerte.

La conformación de "la Liga" no resulta completamente clara, se sabe que estuvo compuesta principalmente por el diputado Manuel Andrade Priego, quien fue el presidente de la Gran Convención en donde se destapó la candidatura gonzalista; el senador doctor Rafael Cepeda, presidente del Comité Ejecutivo de la Liga Democrática; el senador Juan Sánchez Azcona, presidente de la Comisión de Ordenamiento y Corrección de Estilo, y José Quevedo, jefe del Departamento de Propaganda con antecedentes convencionistas. ${ }^{31} \mathrm{~A}$ los hombres que firmaron el programa político deben agre-

${ }^{28}$ Trinidad W. Flores. Telegrama a Roque Estrada, 8 de noviembre de 1919, en Álvaro Matute, Contraespionaje político y sucesión presidencial. Correspondencia de Trinidad W. Flores sobre la primera campaña electoral de Álvaro Obregón, México, Universidad Nacional Autónoma de México, Instituto de Investigaciones Históricas, 1985, p. 95.

${ }^{29}$ El Heraldo de México, 2 de diciembre de 1919, p. 1, 9.

${ }^{30}$ Matute, La carrera..., p. 78.

${ }^{31}$ Carlos Betancourt Cid, Los hombres de la Soberana Convención Revolucionaria, México, Instituto Nacional de Estudios Históricos de las Revoluciones de México/Secretaría de Educación Pública/Congreso del Estado de Aguascalientes-LXII/Universidad Autónoma de Aguascalientes, 2014, p. 372. 
garse otros que estuvieron cerca del divisionario durante este periodo el doctor Luis G. Cervantes, Luis Amieva, los licenciados Aureliano Mendívil y Carlos García, así como el coronel Arturo Lazo de la Vega. Todos ellos con pasado maderista y gran experiencia en el ámbito político-electoral.

Los líderes de la Liga Democrática no mencionan las importantes relaciones militares que había logrado conformar González desde 1912 cuando era uno de los líderes de las fuerzas irregulares de Coahuila y posteriormente durante las luchas contra Huerta y Francisco Villa. Dichas redes político-militares estaban ubicadas hacia 1919 principalmente en el centro-sur y el oriente del país. Entre ellos destacaban los generales Jacinto B. Treviño, Manuel W. González, Sidronio Méndez, Gabriel Gavira, Gustavo Elizondo, Samuel M. de los Santos, Francisco Cossío Robelo y Salvador González Torres, entre otros.

Cepeda, González, Treviño y Elizondo eran de Coahuila, al primero de éstos, González pudo conocerlo desde su participación en la campaña para apoyar a Carranza rumbo a la gubernatura de Coahuila en 1909 y posteriormente se unieron a la lucha contra Huerta en la misma entidad. Los otros tres, González, Treviño y Elizondo, estuvieron bajo su mando en la campaña antihuertista desde 1913. A Jacinto Blas, militar de carrera, teniente técnico de artillería, lo conoció durante la lucha contra Pascual Orozco, ya que éste formó parte del 25o. regimiento irregular de Coahuila. Manuel W. González, tenedor de libros, fue tal vez el hombre más cercano a don Pablo durante varios años: fue su secretario particular y posteriormente jefe de su estado mayor. Elizondo tuvo mayor cercanía con González durante la campaña que se emprendió en Morelos contra los zapatistas en 1916 y en Oaxaca contra los felicistas en 1919.

De la misma forma que Treviño, González y Elizondo, dos oriundos de San Luis Potosí, Sidronio Méndez y Samuel M. de los Santos, dos nacidos en el Distrito Federal, Gabriel Gavira —egresado del Colegio Militar como teniente de ingenieros- y Francisco Cossío Robelo, quien había sido secretario de redacción del periódico México Nuevo, de Juan Sánchez Azcona, en 1909, y un michoacano, Salvador González, estuvieron bajo las órdenes de Pablo González en distintos momentos de 1913 a $1915 .^{32}$

${ }^{32}$ En Diccionario de generales...: Rafael Cepeda, Villa de Arteaga, Coahuila, cinco de diciembre de 1872 (v. I, p. 251-254); Jacinto B. Treviño, Villa Guerrero, Coahuila, 11 de septiembre de 1883 (v. II, p. 1011-1014); Manuel W. González, 29 de octubre de 1889, Lamadrid, Coahuila (v. I, p. 463-464); Gustavo Elizondo, Melchor Múzquiz, Coahuila, 1875 (v. I, p. 325-326); Sidronio Méndez, Río Verde, San Luis Potosí (v. II, p. 653-654); Gabriel 
Como bien mencionó el periódico del gonzalismo, México Nuevo, la mayoría de los entonces "pablistas" habían sido constitucionalistas activos que respetaron el liderazgo de Carranza y posteriormente dieron su voto para que éste ocupara la presidencia en mayo de 1917. Se agregaba en el diario que además muchos de ellos habían sido antes "no sólo amigos personales del hoy presidente de la república, sino sus compañeros de conspiración patriótica, primero, y de decidida acción revolucionaria, después". ${ }^{33}$ Por ello, la corriente que apoyaba a González era respetuosa del gobierno en turno y confiaba en que durante las siguientes elecciones Carranza mostrara una "completa y absoluta neutralidad".

De todos los mencionados, sólo Treviño dio a conocer una circular, firmada en enero de 1920, en la que otorgaba públicamente su apoyo al divisionario neoleonés en la contienda electoral. Aseguraba Treviño que la población se encontraba frente a un problema, la transmisión del poder presidencial, cuya solución no podía causar indiferencia en la población. El general consideraba que el país exigía que ésta fuera "forzosamente pacífica" para conservar "la salud" nacional. Por ello, hacía un formal llamado a los ciudadanos para llevar a la presidencia al ciudadano "más capacitado" que participaría en los comicios. Agregaba en su circular: "El ciudadano González no es un hombre extraordinario, ni el superhombre, pero es un ciudadano honrado, de relevantes dotes civilistas y demócrata a carta cabal, y que ha estereotipado en su programa de gobierno la expresión de sus costumbres y de su mismo ser, marchando rectamente a enfrentarse con los problemas nacionales de urgente resolución". ${ }^{34}$ Dicha postura del futuro gobierno "pablista", a decir de Treviño, estaba marcada por las tendencias civilista, reconstructiva, pacifista y democrática, que constituía para el autor de la circular "la aspiración más alta de todos los mexicanos que no desean seguir viviendo dentro de los procedimientos de los déspotas (por fortuna ya pasados) ni vivir en un mundo de idealismos irrealizables que nos conduzcan al desquiciamiento de nuestra organización social". ${ }^{35}$

Gavira, ciudad de México, 18 de marzo de 1867 (v. I, p. 424-426); Samuel M. de los Santos, Tancahuitz, San Luis Potosí, 1887 (v. II, p. 965-968); Francisco Cosío Robelo, ciudad de México, 29 de abril de 1880 (v. I, p. 277-278); Salvador González Torres, Tacámbaro, Michoacán, 22 de enero de 1885 (v. I, p. 459).

${ }^{33}$ México Nuevo, 14 de febrero de 1920, p. 1.

${ }^{34}$ Ibidem, 18 de febrero de 1920, p. 5.

${ }^{35}$ Idem. 
La "Plataforma mínima" de la Liga Democrática firmada el 27 de noviembre de 1919 constituía un proyecto de gobierno compuesto de XxII incisos, que contenía propuestas de toda índole. A diferencia del manifiesto de la "resaca" de Obregón del 1o. de junio de 1919, la propuesta gonzalina no se componía sólo de aspectos políticos, sino también de carácter social, todo - según el propio texto- con apego a lo establecido en la Constitución de 1917.

Entre las propuestas sociales destacaba el impulso a la educación y a la cultura "para robustecer el alma nacional"; para ello proponía la creación de una Secretaría de Educación y Cultura para federalizar la instrucción pública, además de buscar la autonomía de la Universidad Nacional de México. El problema agrario se buscaría resolver con el impulso de la pequeña propiedad y la dotación de ejidos. En el ámbito laboral la Liga proponía la protección y el fomento a todas las empresas cooperativas "para lograr el abaratamiento de la vida material y procurar mejores condiciones de existencia a las clases proletarias". Asimismo, el posible gobierno gonzalino vigilaría el equilibrio entre el capital y el trabajo para buscar el bienestar del trabajador, pero también de los industriales. ${ }^{36}$ Asimismo, se respetaría el municipio libre.

En lo relativo a la pacificación se consideraba que el camino a seguir, antes de impulsar campañas militares contra los rebeldes, era agotar todos los "recursos de lícitos de acomodamiento y conciliación". ${ }^{37}$ Esta propuesta de la plataforma gonzalista era prácticamente la misma vía que proponía Obregón en su campaña desde mediados de 1919; no obstante, las posibilidades de reunificación de todas las tendencias revolucionarias por parte de González distaban de las del general invicto.

De la mano de lo anterior, la Liga Democrática proponía reducir hasta el mínimo el contingente del ejército efectivo y, paralelamente, crear un esprit de corps en las filas del ejército. Es decir, "hacer comprender, por todos los medios, a generales, jefes, oficiales y soldados, que la fuerza ma-

${ }^{36}$ La "Plataforma Mínima de la Liga Democrática" fue publicada de forma regular desde enero de 1920 en México Nuevo. Posteriormente fue reproducida en Pablo González Miller, El centinela fiel del Constitucionalismo. Un libro excepcional que combate 50 años de engaño, conteniendo 400 facsímiles de documentos históricos auténticos, que expresan la verdad directa y desmienten y modifican la hasta ahora falsa historia oficial de la Revolución Mexicana en la mayor parte de sus conceptos básicos, Saltillo, Textos de Cultura Historiográfica, 1971, p. $478-483$.

${ }^{37}$ Idem. 
terial de que disponen y que la Nación ha puesto en sus manos, es siempre y en todo caso, inferior a la fuerza de la idea" ${ }^{38}$ El ejército no debía utilizarse en tareas de policía urbana ni rural; para estas labores se proponía la creación de una "guardia civil" dependiente de la Secretaría de Gobernación, organización a todas luces similar al cuerpo de rurales que había desaparecido en agosto de 1914 con los acuerdos firmados en Teoloyucan, Estado de México.

La Liga Democrática velaba además por la definición precisa de las responsabilidades de todos los altos funcionarios dependientes del Ejecutivo y proponía la creación de un Departamento de Estadística. Asimismo se buscaría un contacto permanente para impulsar la armonía de acción entre los poderes Ejecutivo y Legislativo.

La política internacional gonzalina se basaba en el "recíproco respeto" con todos los países del orbe. Principalmente, dentro de "la más celosa y rígida observancia" de la soberanía nacional, procurando la amistad con Estados Unidos. En relación con los intereses extranjeros, la Liga proponía la nacionalización de los minerales y "otras substancias que sean distintas de las que ordinariamente constituyen los componentes de la tierra”, es decir, el petróleo, los carburos de hidrógeno. Pero al mismo tiempo se aseguraba reconocer el derecho sobre el subsuelo adquirido por algunos particulares con base en las leyes vigentes. ${ }^{39}$

Pese a lo anterior, la propuesta de la Liga era elitista si se le comparaba con los postulados de Obregón reflejados en su propaganda y en sus discursos ofrecidos en su recorrido por la república mexicana. Dicho "populismo obregonista" puede entenderse como una fórmula política en la que "el pueblo", entendido como un "conjunto social homogéneo y como depositario exclusivo de valores positivos, específicos y permanentes", es base de "inspiración y objeto constante de referencia". Dicha doctrina suele ser liderada e impulsada por un personaje de personalidad carismática, como lo era Obregón, característica que evidentemente no poseía Pablo González. Para el general invicto, la legitimidad provenía del grueso del pueblo, que aparecía más como un recurso retórico, sin una definición específica. El objetivo primordial de sus mensajes era la reconciliación de los diversos sectores, principalmente de los trabajadores, del campo y de la fábrica, con

${ }^{38}$ Idem.

${ }^{39}$ Idem. 
los patrones, con los "poderosos". ${ }^{40}$ Esta postura contrastó notablemente con lo realizado por los otros candidatos, y aunque González lo plasmó en su "Plataforma mínima" de la Liga Democrática nunca hizo lo mismo en una gira por el país, factor que le restó posibilidades de ganar adeptos.

Finalmente, el neoleonés aceptó su postulación el 10 de diciembre. ${ }^{41}$ No obstante, protestó como candidato de la Liga Democrática hasta el 13 de enero de 1920, cuando, podría decirse, inició su campaña siguiendo lo que Carranza había pedido en su manifiesto de un año atrás, esperar las ansias electorales y arrancar las giras políticas hasta $1920 .{ }^{42}$

El Monitor Republicano repitió un argumento del año anterior: Pablo González había aceptado ser el candidato de la plataforma que parecía convertirse en el Partido Neoconservador de México, antítesis del Partido Liberal Constitucionalista. El gonzalismo buscaba derribar todo lo que la revolución había cimentado, desde los avances sociales hasta los políticos. ${ }^{43}$ En Excélsior se criticó el programa de la Liga Democrática debido a que era demasiado extenso y "retrógrada" ya que a lo largo de los últimos años se había demostrado que los manifiestos, planes y programas políticos elaborados al calor de la lucha armada eran sinónimo de fracaso, fundamentalmente porque estaba auspiciado por y para un militar. ${ }^{44}$

González no contó de inmediato con un periódico, pese a creerse que había adquirido la imprenta de The Mexican Herald. Fue a finales de 1919 cuando, con dirección en Tacuba núm. 6, se creó el diario México Nuevo -homónimo de la publicación maderista- con ocho páginas en formato tabloide y un precio de cinco centavos, bajo la dirección de Juan Sánchez Azcona, directivo de la Liga Democrática. Dicho periódico, de escasa circulación $-\mathrm{y}$ difícil acceso para su investigación-, tardó en aparecer, ya que, como se ha visto, los otros periódicos nunca cesaron en sus críticas hacia el candidato de la Liga.

La Liga Democrática, el Partido Liberal Antirreeleccionista, el Partido Confederado del Trabajo, el Gran Partido Liberal Progresista, y todos los

${ }^{40}$ Norberto Bobbio y Nicola Mateucci, Diccionario de política, 2 v., México, Siglo XXI, 1982, v. II, p. 1247-1248.

${ }^{41}$ El Heraldo de México, 11 de diciembre de 1919, p. 1; El Demócrata, 13 de diciembre de 1919, p. 1.

${ }^{42}$ El Universal, 14 de enero de 1920, p. 3-4; Charles C. Cumberland, La Revolución mexicana. Los años constitucionalistas, México, Fondo de Cultura Económica, 1975, p. 365.

${ }^{43}$ El Monitor Republicano, 28 de noviembre de 1919, p. 1.

${ }^{44}$ Excélsior, 21 de enero de 1920, p. 3. 
demás partidos y clubes que trabajaban por la candidatura de González recomendaban a sus simpatizantes la suscripción a México Nuevo, cuyo costo era de $\$ 1.50$ al mes, o de $\$ 6.00$ hasta el 31 de julio, momento en que se dejaría de publicar por la realización de los comicios. El periódico aseguraba distribuirse en toda la república mexicana.

Juan Sánchez Azcona tenía amplia experiencia en el ramo periodístico, ya que colaboró en El Imparcial, fundó El Presente, dirigió el antiguo México Nuevo de corte maderista y apoyó al presidente Francisco I. Madero en la incesante batalla contra el "cuarto poder" al crear, con capital de Gustavo A. Madero, Nueva Era. ${ }^{45}$ El subdirector era Arturo Lazo de la Vega, el administrador interino C. de María y Campos, además contaba con editorialistas que firmaban bajo diversos pseudónimos como el de Ariel Gabac y Ego Sum, y artículos relacionados con la cuestión agraria firmados por el ingeniero Gilberto Fabela. A diferencia de los otros diarios, México Nuevo no tuvo caricaturista. Se trataba a todas luces de un grupo editorial de gran experiencia política que habría de crear una imagen favorable de González en su campaña.

\section{El candidato entrelíneas de México Nuevo}

Llegado el segundo mes de 1920 los aspirantes para ocupar la silla presidencial estaban completamente definidos. El ingeniero Bonillas no había iniciado formalmente su campaña presidencial, pero desde las arcas gubernamentales se preparaba la propaganda para recibirlo en marzo del mismo año. Obregón ya iniciaba una nueva fase de su recorrido por el país; después de visitar parte del centro y del occidente, se alistaba para viajar por el norte de la república. Por su parte, González se mostraba dubitativo, legalista, al parecer demasiado calculador en espera de jugar sus cartas de la mejor forma posible antes de dar un paso en falso; por ello, no había iniciado una campaña al estilo estadounidense, como la de Madero u Obregón; era según un editorialista de México Nuevo, "el candidato modesto", ¿̇realmente era correcta dicha apreciación?

En febrero se incrementaron los trabajos de propaganda de la Liga Democrática y paralelamente se intensificaron las críticas a los contrincantes del divisionario neoleonés en la prensa gonzalista. Cada semana se publi-

${ }^{45}$ Cruz García, Nueva Era y la prensa..., p. 129-143. 
caron en México Nuevo las "Instrucciones del Comité Ejecutivo de la 'Liga Democrática' a los sub-comités, delegados, propagandistas y en general a todos aquellos que se interesen en el triunfo de la candidatura del ciudadano general Pablo González a la presidencia”. Se trataba, más que de una serie de objetivos que debían cumplir los propagandistas para crear nuevos clubes e impulsar al gonzalismo, de un listado comparativo entre González y Obregón de corte propagandístico, cuya distancia principal entre los divisionarios, según el periódico, estribaba en los procedimientos. Para los gonzalistas, los obregonistas trataban

de proseguir el viejo sistema de deslumbrar a los sufridos trabajadores, abusando de su ignorancia por medio de ofrecimientos demagógicos, augurándoles durante su gobierno un bienestar que está muy lejos de ser duradero, puesto que lo cifran en la preponderancia de un grupo y no en el estímulo que el propio esfuerzo y la constancia señalan y consiguen como camino seguro para el éxito. Ellos entienden la revolución como medio de venganza, y nosotros la entendemos como medio de reparación y justicia. ${ }^{46}$

Para los editorialistas de México Nuevo, Obregón tenía una responsabilidad histórica "indeclinable" por haber sido uno de los principales jefes del movimiento constitucionalista que derrocó a Huerta y que a su debido tiempo le sería "exigida, según sus merecimientos y errores". No obstante, el general invicto al separarse del gobierno, en mayo de 1917, cometió un acto de traición a la causa que defendía. Dicha actitud demostraba "lo voluble de sus convicciones" y la poca reflexión que concedía a actos de relevante trascendencia. Una vez retirado de la vida pública, Obregón había sido inspirado por la "conveniencia personal" y no por el bien general. Contrariamente a la actitud personalista del candidato sonorense, el general González había tenido una actitud muy distinta desde la revolución maderista, según sus seguidores, "siempre estuvo dispuesto, en la lucha y al quedar constituido el Gobierno de la Revolución, a restarle su cooperación para que se consolidara, sin rehuir la responsabilidad de sus actos". Sin duda alguna, uno de los carrancistas más connotados que nunca había mostrado abiertamente sus ambiciones personales era "don Pablo", a diferencia de la independencia política que buscó el general invicto desde finales de 1914 cuando no se opuso a que Carranza y Villa abandonaran sus

${ }^{46}$ México Nuevo, 10 de febrero de 1920, p. 4. 
respectivos puestos al mando de los ejércitos revolucionarios para que él paulatinamente emergiera como el hombre que tomara las riendas del país.

Por ello en las instrucciones del Comité de Propaganda de la Liga Democrática se pedía a sus correligionarios que "predicaran para la paz y el trabajo", ya que el general González triunfaría en las elecciones por medios legales y no a través de una nueva revolución.

Poco después, desde mediados de febrero, se dio a conocer una lista más definida de las instrucciones que debían seguir los "delegados propagandistas del pablismo”. En ellas se insistía en la necesidad de observar una "conducta intachable" que le diera prestigio a la Liga Democrática, así como en respetar al gobierno en turno y a los otros candidatos. Asimismo se ponía énfasis en la conveniencia de que los ciudadanos analizaran las posturas de todos los contendientes y que los propagandistas explicaran, para aquellos que no lograran comprender con facilidad, la plataforma básica gonzalista cuyo fin principal era implantar un "buen gobierno" en el país. ${ }^{47}$

Entre los diez puntos que tenía la lista, destacaba el segundo "Respetar todos los credos políticos y religiosos”. Este punto estaba evidentemente vinculado con la postura anticlerical que Obregón y sus hombres más cercanos habían llevado a cabo en los territorios que habían ocupado durante las campañas militares entre 1913 y 1916, de gran impacto en una sociedad eminentemente católica.

Paralelamente, el 11 de enero de 1920 la estrategia para la postulación del candidato oficial sufrió importantes modificaciones. Federico Montes, gobernador de Guanajuato desde agosto del año anterior, tomó la dirección de la campaña bonillista. ${ }^{48}$ Montes redactó junto a los gobernadores de Querétaro, Salvador Argáin; de Jalisco, Luis Castellanos y Tapia; y de Severino Martínez, de San Luis Potosí, una carta para invitar a los ejecutivos locales de todos los estados para que asistieran del 6 al 9 de febrero a la ciudad de México a una reunión para discutir "el grave asunto de transmisión pacífica del poder, con motivo de las elecciones presidenciales". ${ }^{49} \mathrm{El}$ "Cónclave de Gobernadores", como lo llamó la prensa, se llevó a cabo en la

${ }^{47}$ Ibidem, 17 de febrero de 1920, p. 1.

${ }^{48}$ Álvaro Matute, Las dificultades del nuevo Estado, México, El Colegio de México, 1995 (Col. Historia de la Revolución Mexicana, 7), p. 184. Todo parecía indicar que Luis Manuel Rojas, hasta ese momento jefe de la campaña de Bonillas, no había cubierto las expectativas debido a que la gira del ingeniero ni siquiera había iniciado formalmente; Trinidad W. Flores. Telegrama a Roque Estrada, 10 de enero de 1920, en Matute, Contraespionaje..., p. 120.

${ }^{49}$ Matute, La carrera..., p. 85. 
fecha acordada en el Automóvil Club, ubicado en el bosque de Chapultepec. La lista de ausentes a la reunión reflejó el tenso ambiente político que se vivía, ya que no acudieron Adolfo de la Huerta, de Sonora; el general Enrique Estrada, de Zacatecas; el general Carlos Greene, de Tabasco, ni el ingeniero Pascual Ortiz Rubio, de Michoacán, todos de tendencia obregonista.

Días más tarde, el 18 de enero, El Demócrata publicó el manifiesto del Partido Nacional Democrático con el que se lanzó oficialmente la candidatura de Bonillas. El texto aseguraba que el gobierno no intentaba imponer a ningún candidato y, en cambio, buscaba impulsar la libertad del sufragio. Los gobernadores asistentes mostraron un fuerte compromiso con el presidente Carranza y dejaron entrever que los partidarios obregonistas preparaban una nueva guerra civil. ${ }^{50}$ ¿Acaso buscaron calmar los ánimos electorales? Si eso deseaban en realidad consiguieron todo lo contrario ya que con el destape de una candidatura oficial los ánimos se caldearon todavía más.

Juan Sánchez Azcona en las páginas de México Nuevo pidió que la junta de gobernadores fuera pública para que no quedara en el aire un posible fraude electoral preparado desde el seno de la misma. ${ }^{51}$ Días después el mismo periódico publicó un llamado a la junta de gobernadores para que no se desconfiara de sus actividades: "No tenemos por qué dudar de vuestro tino, de vuestras buenas intenciones. Pero disipad sospechas por cuantos medios podáis, pues tan nuevo es entre nosotros lo que estáis haciendo que habéis creado expectación en la nación entera". ${ }^{52}$

Los editoriales y las opiniones sobre Obregón publicados en México Nuevo fueron contradictorios. Por un lado, Sánchez Azcona afirmaba respetar al candidato sonorense, pero no así sus métodos; la definición de la plataforma política y del programa de gobierno debía ser primero que el candidato. El director del periódico gonzalista afirmaba que sería un error negar que Obregón tuviera muchos partidarios, pues su candidatura tenía orígenes "bien racionales", definidos y lógicos, después de los sucesos de los últimos diez años. Aseveraba también que no se trataba de "una candidatura de invernadero" ya que representaba "tendencias, afinidades y orientaciones" que tenían "razón de ser" entre las agrupaciones que las cultivaban y propagaban. "Así pensamos - continuaba el editorialista- los

${ }^{50}$ El manifiesto apareció en El Universal, 11 de febrero de 1920, p. 1; Pedro Castro, Álvaro Obregón. Fuego y cenizas de la Revolución Mexicana, México, Era/Consejo Nacional para la Cultura y las Artes, 2009, p. 71-72.

${ }^{51}$ México Nuevo, 2 de febrero de 1920, p. 1.

${ }^{52}$ Ibidem, 7 de febrero de 1920, p. 1. 
pablistas acerca del obregonismo y creemos que los obregonistas han de pensar de modo análogo acerca del pablismo". ${ }^{53}$

No obstante, Sánchez Azcona aseveró que el obregonismo había actuado de "extraña manera" al anteponer la elección del ciudadano que sería su candidato antes de definir su programa de gobierno. En matemáticas, afirmaba Sánchez, "aprendimos que el orden de los factores no altera el producto. Pero no consideramos aplicable tal axioma a la sociología ni a la política. Por eso nosotros, en la LIGA DEMOCRÁTICA, procedimos de modo distinto, y no estamos arrepentidos de ello, porque el sistema que seguimos nos ha permitido alcanzar una organización más compacta, más espontánea, más sólida y más dilatada [...]". ${ }^{54}$

Para el director de México Nuevo la protesta de González como candidato de la Liga Democrática fue un pacto, mientras que cuando concluyera la reunión de los obregonistas, tras la que se formó el Centro Director Obregonista, sería un simple juramento a su candidato. De la mano de este argumento, otro que apareció constantemente fue el del uso de la violencia por parte de los obregonistas para alcanzar las metas que se habían fijado, en contraste con el "civilismo" de González. ${ }^{55}$ Tal estrategia de propaganda fue utilizada como refutación de lo que se afirmaba principalmente en Excélsior, periódico que encasilló a González y a Obregón en la corriente militarista que buscaba ocupar la silla presidencial. Por ello, esta táctica fue utilizada todavía con mayor frecuencia en el periódico obregonista El Monitor Republicano. ${ }^{56}$

El 6 de febrero, el general Obregón, de gira por Aguascalientes, criticó a sus contendientes por su negación de recorrer el país en una gira de propaganda para conocer las necesidades de cada una de las entidades federativas. Como respuesta, Sánchez Azcona redactó un editorial en el que afirmaba que todo se realizaría a su debido tiempo y pedía a Obregón que no se desesperara, pues González iría a todos los estados del país que le fuera posible a decir a la población cuáles eran los "grandes anhelos de reforma de que se siente animado; cuál es la interpretación que debe dar a todos y cada uno de sus principios políticos; cuáles son las necesidades públicas

${ }^{53}$ Ibidem, 2 de febrero de 1920, p. 1.

${ }^{54}$ Idem.

${ }^{55}$ México Nuevo, 3 de febrero, p. 3.

${ }^{56}$ El Monitor Republicano, 4 de octubre de 1919, p. 1, 4 y 10. 
que la Nación necesita satisfacer de preferencia; en una palabra, cuál es la obra de gobierno que se propone realizar". ${ }^{57}$

En otro editorial se aseguró que "no por mucho madrugar" se obtendrían mejores resultados en la gira de propaganda. Sánchez Azcona criticaba la "inusitada impaciencia" de El Monitor Republicano por el hecho de que el general González aún no iniciaba su recorrido por el país. Agradecía sarcásticamente el interés del diario, pero aseguraba que su candidato hacía todas las cosas "con orden y previsión": "Hemos calculado, sobre datos precisos, que la gira de don Pablo no requerirá tanto tiempo como los obregonistas han calculado que requería la de su candidato". La gira del neoleonés tenía un carácter "muy distinto" a la de Obregón, según el director del diario gonzalista.

Asimismo, mientras el sonorense iba en su gira "en pos de ovaciones 'fetichistas' a su gallardía personal” y tenía que explicar "en líricos y deshilvanados discursos" las aspiraciones de su partido, González realizaría la suya para

RATIFICAR ante sus partidarios propósitos de gobierno que ellos ya conocen de antemano de modo exacto y preciso, y en vez de solicitar ovaciones tan efímeras como callejeras, va a ponerse en contacto con sus partidarios de cada región para CONOCER mejor sus necesidades y sus legítimas aspiraciones a fin de estar en aptitud de satisfacerlas, en el límite de sus fuerzas, una vez que el voto popular lo lleve al poder. Don Pablo discursará y banqueteará menos, pero OBSERVARÁ más. ${ }^{58}$

Para Sánchez Azcona las giras electorales se habían convertido en una necesidad democrática; pero era preciso darles el carácter que debían tener "sin confundirlas con los paseos farandulescos con que se anuncian las carpas de saltimbanquis". Cada palabra que el candidato pronunciara ante el pueblo, debía tener "un valor preciso y exacto," para que "ese pueblo" la comprendiera y la analizara correctamente. El candidato no iba a exaltar a la población, sino a convencer y a persuadir.

Reflejo de su candidato, los partidarios de González eran los hombres más "serios y reflexivos", cualquiera que fuera el sector social al que pertenecieran. No se trataba, haciendo mofa de los posibles partidarios que conseguía Obregón en su gira por la república, de las "turbas inconscientes,

57 México Nuevo, 12 de febrero de 1920, p. 3.

${ }^{58}$ Ibidem, 16 de febrero de 1920, p. 1. 
abundantes en todas partes y en todo tiempo, que siguen mecánicamente a la primera charanga que se les presenta, para olvidar unos momentos después el tono de la música que les tocaron y para agregarse a la nueva charanga que llegue". Los gonzalistas eran los ciudadanos "conscientes y convencidos de las necesidades nacionales y del delicado momento histórico" que se vivía. ${ }^{59}$

Paralelamente, los gonzalistas llamaron "manifiesto primitivo" al redactado por Obregón en junio de 1919 ya que no coincidía con las verdaderas necesidades del país, pues ni siquiera contenía propuestas sociales. Asimismo, aseguraron que los obregonistas copiaron diversos postulados aparecidos en la plataforma mínima de la Liga Democrática. ${ }^{60}$

Según México Nuevo, su candidato tenía un gran apoyo en toda la república, Puebla, Veracruz, Yucatán, Zacatecas, el DF e incluso en todo el noroeste, cuyos editoriales afirmaban que Obregón era mal recibido en localidades como Álamos, Sonora. Destacaron también el apoyo del que gozaba entre los estudiantes de la capital del país. ${ }^{61}$ Mención especial merece un artículo de un tal Teódulo Catalán, según el cual los surianos agradecían el bienestar y el trabajo que había impulsado don Pablo en la entidad. ${ }^{62}$ No obstante, un posible pacto con los zapatistas sólo era posible en artículos y notas propagandísticas, ya que dicha alianza había quedado descartada desde abril de 1919 cuando González había planeado con el apoyo de Guajardo la traición y asesinato de Zapata.

Por otro lado, González no podía tener una buena relación con los obreros en gran medida porque éstos desconfiaban de él tras la forma en que intervino contra la Casa del Obrero Mundial tres años antes. Al iniciar 1916, en un manifiesto González aseguró que los obreros de la Casa eran un foco de alerta debido a que consideraba como un error que algunos de sus líderes obserban a sus organizaciones como "una especie de instituciones oficiales con autoridad casi gubernativa para imponer sus exigencias [...]". Opinaba González que los obreros actuaban con "violentos reproches" contra las autoridades carrancistas, situación que no sería tolerada y en caso de proseguir se tomarían las medidas necesarias. Parafraseando a Benito Juárez, González juzgaba que sólo actuaría con base en el principio “del respeto al derecho ajeno, como base para la existencia de la paz”. Pronto

\footnotetext{
${ }^{59}$ Idem.

${ }^{60}$ México Nuevo, 24 de febrero de 1920, p. 3.

${ }^{61}$ Ibidem, 14 de febrero de 1920, p. 1.

${ }^{62}$ Ibidem, 20 de febrero de 1920, p. 3.
} 
fueron aprehendidos varios líderes de la Casa en diversos estados del país debido a que sus acciones tendían a "trastornar el orden público". Además fue clausurada la sede de la Casa del Obrero Mundial de Monterrey por el general Jacinto B. Treviño.

El 4 de febrero del mismo año por órdenes del Primer Jefe se procedió a solicitar a los mundiales la desocupación de la Casa de los Azulejos, antiguo Jockey Club. González informó a Carranza que debido a que los obreros no habían atendido la orden de su Cuartel General fueron arrestados los miembros de la mesa de la directiva de la Casa y fueron selladas las puertas del edificio. En realidad el neoleonés había ingresado a las instalaciones acompañado de aproximadamente $\mathbf{5 0 0}$ hombres armados que destruyeron las instalaciones del periódico Ariete, las instalaciones de la escuela racionalista y la biblioteca, y corrió a los obreros que se hallaban en el palacio de los azulejos. ${ }^{63}$ Estas acciones eran apenas los prolegómenos de la posterior huelga general cuya repercusión fue el fin de la Casa en mayo de 1916.

Además un posible pacto con el líder de la Confederación Regional Obrera Mexicana, Luis N. Morones al parecer había sido descartado por el propio neoleonés. Morones se adhirió al obregonismo a través de un "pacto secreto" en diciembre de 1919 y formó el "brazo político" de la confederación, el Partido Laborista Mexicano. ${ }^{64}$

El 25 de febrero en una entrevista dada a México Nuevo, González dejaba claro que la imposición de Bonillas daría un giro a la contienda electoral; no obstante, todavía aseguraba que respetaría cualquiera que fuera el resultado de los comicios. Sobre el otro candidato aseveró: "La postulación del señor Obregón es muy conveniente para el país, porque él y yo sintetizamos la contienda en términos de sana democracia y los que en realidad somos objeto de lo que es propiamente el sufragio de los hombres". ${ }^{65}$

Después de lo antes narrado, la campaña de González fue la que tuvo menor difusión en El Heraldo de México y El Monitor Republicano, no así en El Universal - cuyo dueño, Félix F. Palavicini, se llegó a especular que sería candidato a senador por la Liga Democrática ${ }^{66}$ ni en Excélsior, periódico que continuó su campaña contra el militarismo. ¿Por qué ocurrió dicha

${ }^{63}$ Anna Ribera Carbó, La Casa del Obrero Mundial. Anarcosindicalismo y revolución en México, México, Instituto Nacional de Antropología e Historia, 2010, p. 205-208.

${ }^{64}$ Barry Carr, El movimiento obrero y la política en México, 1910-1929, 2 v., México, Secretaría de Educación Pública, 1976, v. I, p. 147.

${ }^{65}$ México Nuevo, 25 de febrero de 1920, p. 1, 7.

${ }^{66}$ Ibidem, 29 de febrero de 1920, p. 1. 
situación? ¿Acaso González era un personaje relevante para los otros candidatos? Las principales razones de que ello ocurriera fueron, en primer lugar, que el candidato neoleonés no realizó una campaña de propaganda de gran impacto, como sí lo hicieron Obregón y Bonillas desde inicios de $1920 ;{ }^{67}$ y en segundo lugar no se le atacó porque podía convertirse en un posible aliado.

Desde finales de noviembre, se hablaba en los círculos políticos cercanos a Obregón y a González sobre la posibilidad de que existiera un acercamiento entre ambos candidatos. Tanto en El Heraldo de México como en El Monitor Republicano dedicaron gran parte de sus líneas a la crítica del candidato cercano a Carranza, el ingeniero Ignacio Bonillas, y la figura de González se diluyó conforme avanzó 1920.

No obstante, antes del arribo de Bonillas al país, del que todavía en febrero se aseguraba en México Nuevo que posiblemente no aceptaría su candidatura, ${ }^{68}$ la prensa obregonista llevó a cabo una estrategia que le permitiera criticar a sus dos oponentes. Mostró los vínculos entre gonzalistas y bonillistas con el fin de debilitar ambas candidaturas. Se preguntó el editorialista del 16 de marzo de 1920: “¿qué hará don Pablo si Bonillas acepta la candidatura?", y destacaba que el movimiento obregonista esperaba tranquilamente a "su enemigo para desplazarlo, en el terreno político y con las armas que da la ley". ${ }^{69}$ De hecho, los vínculos entre González, Bonillas y el gobierno habían aparecido en El Monitor Republicano desde enero del mismo año cuando el neoleonés lanzó su candidatura. ${ }^{70}$ Estos rumores, el del pacto con el gobierno y la posibilidad de renunciar a su candidatura, se desmintieron cotidianamente en México Nuevo de enero a marzo de 1920.

¿Existió el acercamiento entre Bonillas y González? Ambas candidaturas fueron ampliamente vinculadas en las páginas de El Heraldo de México durante los últimos días de marzo y abril. Después del arribo de Bonillas, dicho periódico afirmó que se llevaría a cabo una reunión entre los tres candidatos a la presidencia -Obregón, Bonillas y González-para procurar que la lucha electoral fuera libre y que ninguno de los candidatos

\footnotetext{
${ }^{67}$ Blasco Ibáñez, El militarismo mejicano..., p. 66-67.

${ }^{68}$ México Nuevo, 1, 15 y 28 de febrero de 1920, p. 1.

${ }^{69}$ Ibidem, 16 de marzo de 1920, p. 1.

${ }^{70}$ El Monitor Republicano, 4 y 8 de enero de 1920, p. 3.
} 
tuviera "ni indirectamente" el apoyo del gobierno. ${ }^{71}$ No obstante, la supuesta reunión a finales de marzo fue un rumor más creado desde las páginas del rotativo, pues Bonillas desmintió siquiera haber sido invitado a conferenciar sobre las candidaturas, y días después hizo lo propio Obregón, aunque este último ya entablaba conversaciones con González. ${ }^{72}$

El pacto con Obregón, la ocupación de la ciudad de México y el fracaso gonzalista

Al iniciar abril de 1920, un mes decisivo en la Revolución Mexicana, se publicó una propuesta de Pablo González en la que pedía a los candidatos renunciar a sus postulaciones, y elegir otro ciudadano que contara con prestigio para que ocupara la presidencia de la república. ${ }^{73}$ La nota cobraba sentido debido a que ese mismo día se informaba que el gobierno del estado de Sonora había roto definitivamente las relaciones con el gobierno de Carranza. Sin duda era parte de una estrategia periodística para demostrar que una posible solución estaba por llegar y el movimiento sonorense sería detenido rápidamente.

Ese mismo día El Heraldo de México publicó una entrevista realizada a Bonillas en la que aseveraba que aceptaría el fallo popular y rechazaba el acuerdo de González:

Por mi parte declaro que jamás he tenido ambición alguna para llegar a ningún puesto público de grande o pequeña categoría, y que si he aceptado entrar en la presente lucha es porque considero que el civilismo es el coronamiento definitivo que debe tener una revolución que se hizo fundamentalmente por combatir los funestos resultados del militarismo, inmiscuido como fuerza política dirigente de los destinos del país.

Tengo la seguridad de que en la derrota mis amigos sabrán respetar el resultado de los comicios, sometiéndose democráticamente a la voluntad de la mayoría y que en el triunfo, estando apoyado por el pueblo, sabremos conquistar para el país el orden y la paz. ${ }^{74}$

${ }^{71}$ El Heraldo de México, 24 de marzo de 1920, p. 1.

${ }^{72}$ Ibidem, 26 de marzo de 1920, p. 1, 8; El Monitor Republicano, 13 de abril de 1920, p. 1,4 .

${ }^{73}$ El Heraldo de México, 10 de abril de 1920, p. 1, 9.

${ }^{74}$ Ibidem, 10 de abril de 1920, p. 1, 9. 
El Monitor Republicano se mostró en contra del postulado de González, pues no podía renunciar a los ideales democráticos y eliminar las candidaturas por sí mismo. ${ }^{75}$

Los acontecimientos políticos se presentaron de forma muy distinta a lo publicado en las notas periodísticas. Entre su arribo a la capital para declarar sobre sus supuestos vínculos con el exgeneral felicista Roberto Cejudo y su huida de la ciudad de México, Obregón buscó tener una entrevista con el general Pablo González, a la que éste accedió. La reunión se efectuó el domingo 11 de abril de 1920 a las cinco de la tarde en el jardín del restaurante de Chapultepec. Miguel Alessio Robles años después aseguró que antes de salir Obregón le "suplicó que hablase a los periódicos comunicándoles el acontecimiento político que se iba a registrar. Acudieron, presurosos, redactores y fotógrafos al famoso restaurante. Al día siguiente los periódicos hablaron de esa entrevista. Era lo que deseaba el caudillo sonorense para que todos los subordinados de don Pablo González supieran que había un cordial entendimiento entre ambos divisionarios". ${ }^{76}$

¿Por qué y para qué reunirse? Las posibilidades de un pacto no fructificaron en 1919, como se observó líneas atrás. No obstante, en diciembre de dicho año en El Heraldo de México se dio a conocer que "llegado el caso" los obregonistas y los gonzalistas se unirían para contrarrestar la "influencia oficial" favorable al bonillismo. ${ }^{77}$ Prieto Laurens aseguró que durante los primeros meses de 1920, en el Centro Director Obregonista, se habló de la necesidad de vincular a los dos grandes grupos de oposición al carrancismo: el gonzalismo, que no había roto con el presidente, y el obregonismo. Diversos acontecimientos de la ciudad de México y Tampico durante la campaña obregonista, en donde resultaron detenidos y golpeados varios

${ }^{75}$ El Monitor Republicano, 11 de abril de 1920, p. 3.

${ }^{76}$ Miguel Alessio Robles, Memorias, 4 v., México, Instituto Nacional de Estudios Históricos de las Revoluciones de México/Gobierno del Estado de Coahuila, 2010, v. II, p. 46-47. Prieto Laurens se incluye en la invitación a los periodistas: "Yo me encargué, juntamente con el Sr. Lic. D. Miguel Alessio Robles, de invitar a los reporteros y fotógrafos de la fuente política, de todos los diarios y revistas de esta Capital, quienes se apresuraron a concurrir al inusitado encuentro, concediéndole una importancia extraordinaria y excepcional, dada la intransigencia personalista de las luchas políticas de aquélla época y las profundas diferencias que había, de tiempo atrás, entre Obregón y don Pablo, y, por consiguiente, entre sus respectivos partidarios y amigos". Jorge Prieto Laurens, Cincuenta años de política mexicana. Memorias políticas, México, Editora Mexicana de Periódicos, Libros y Revistas, 1968, p. 77.

${ }^{77}$ El Heraldo de México, 16 de diciembre de 1919, p. 1. 
obregonistas, hicieron que se retomara el tema y se discutió "la forma de unificar, coordinar, o cuando menos, neutralizar a los 'gonzalistas' que no se decidían a romper con el gobierno de Carranza y que atacaban tibiamente la imposición bonillista". Dicha postura coincidía efectivamente con lo publicado en México Nuevo.

Prieto relató que el general Francisco R. Serrano le había encargado contactar a sus "viejos amigos y compañeros del Cooperatista", sobre todo al general Jacinto B. Treviño, expresidente del Partido, a los licenciados José Luis Almogábar y Cecilio Garza González, así como al general Rafael Cepeda, "ex regidores y ex alcalde del Ayuntamiento Cooperatista de 1919, respectivamente", varios de ellos miembros de la Liga Democrática, sobre todo Cepeda, quien era uno de los principales líderes. Todos ellos le recomendaron convenir una reunión con Obregón, pues ambos compartían la oposición a Bonillas. En un primer momento, los acercamientos con González se complicaron, pero el general Treviño, quien era una de las personas más cercanas al candidato influyó para que finalmente se efectuara la tertulia. ${ }^{78}$

Llegado ese momento, era evidente que los cálculos de González no habían sido los correctos y miró con preocupación y cierto resentimiento que Carranza, su jefe desde 1913, no encontrara en él al candidato para sucederlo. La campaña de Bonillas, con un pasado más cercano al Grupo Sonora, pero completamente leal al coahuilense fue decepcionante para González por lo que comenzó a preparar una nueva estrategia, de nuevo silenciosa, que incluía pactar con Obregón en busca de una salida a su compleja situación política.

Obregón arribó al restaurante acompañado del senador licenciado Cutberto Hidalgo, Rafael y Juan Zubarán Capmany, tres personajes cercanos a Obregón desde 1914; después se agregaron Miguel Alessio Robles y el secretario particular del general invicto, Fernando Torreblanca. González tuvo como comitiva a Sánchez Azcona, al doctor Luis G. Cervantes, al licenciado Aureliano Mendívil, y al coronel Arturo Lazo de la Vega, miembros de la Liga Democrática y colaboradores de México Nuevo.

Efectivamente fueron ciertas las apreciaciones de Alessio Robles y Prieto Laurens, los principales diarios del país dieron amplia difusión al encuentro entre González y Obregón en Chapultepec. Cada rotativo tuvo su propia interpretación de lo acaecido. Por un lado, el periódico peleceano argumentó que el encuentro había sido casual, pero se podía inferir que "se

${ }^{78}$ Prieto Laurens, Cincuenta años de política..., p. 76-77. 
habían encontrado" para charlar en torno de la imposición bonillista. Un reporter de El Monitor acudió a la casa de Miguel Alessio Robles donde aseguró haber entablado una conversación con Obregón, y narró los hechos de la siguiente forma:

Acompañado de los señores general don Jacinto Treviño y licenciado don Rafael Zubaran Capmany, el señor Obregón se dirigió ayer por la tarde, al histórico bosque. Después de recorrer las frondosas avenidas, cerca de las cinco, se aproximaron al restaurant a donde penetraron para tomar una taza de té. En una de las mesas del café, se encontraba el general don Pablo González, acompañado de los señores don Juan Sánchez Azcona, director de nuestro colega, México Nuevo, Aureliano Mendivil y [el] doctor don Luis G. Cervantes. Cuando el señor Obregón los distinguió, espontáneamente se acercó a ellos para saludarlos, sentándose en torno de la misma mesa para conversar unos momentos. La conversación, que fue breve, versó, sobre los últimos sucesos políticos, especialmente sobre las maniobras oficiales para imponer al señor ingeniero don Ignacio Bonillas.

¿Y eso fue todo? - preguntamos ansiosos.

-Eso fue todo - nos contestaron.

Y es bastante, después de todo, dijimos al salir de la residencia del candidato popular. ${ }^{79}$

Artículos y editoriales subrayaron la virtual unión entre González y Obregón. ${ }^{80}$ El Heraldo de México se preguntó: “¿Llegarán a unificarse los elementos del pablismo y del obregonismo?; para el periódico la reunión parecía haber sido premeditada ya que, desde las primeras horas del día, se corría el rumor de que ambos candidatos se encontrarían en el restaurante. No obstante, el rotativo no se atrevió a confirmar de lo que se había tratado en la tertulia en la que ambos personajes habían departido: "Si algo grave o importantísimo trataron, esto por ahora ha quedado en el misterio, aun cuando es indudable que la trascendencia del hecho, no tardará en hacerse del conocimiento público" ${ }^{81}$ ¿Por qué optaron por tener una actitud tan cautelosa los diarios capitalinos? Al parecer era preferible hablar de un

${ }^{79}$ El Monitor Republicano, 12 de abril de 1920, p. 1.

${ }^{80}$ El periódico del Partido Liberal Constitucionalista afirmó lo siguiente: "Como era natural, ver reunidos a los dos candidatos presidenciales, que no hace mucho tiempo aún el público creía enormemente distanciados hasta el punto de que ambos aparecían como únicos contendientes, era algo extraordinario y sensacional”, El Monitor Republicano, 12 de abril de 1920, p. 3.

${ }^{81}$ El Heraldo de México, 12 de abril de 1920, p. 1, 11. 
"encuentro casual" para evitar cualquier suspicacia por parte del gobierno sobre un inminente levantamiento militar. El presidente de la república sabía que una nueva lucha armada podía iniciar en cualquier momento.

La reunión entre los generales causó un gran revuelo entre los militares más cercanos a Carranza, entre ellos Francisco Murguía, Manuel M. Diéguez, Juan Barragán y Cándido Aguilar. Esto se debía en gran medida a que facilitó la adhesión de los gonzalistas a la causa obregonista y, posteriormente, aguaprietista, como el caso de Fortunato Maycotte. Al mismo tiempo, este nuevo vínculo trajo consigo la unión de diversos cabecillas revolucionarios dispersos en el país. "Muy pocas personas se enteraron de que no hubo tal acuerdo y de que sólo fue un truco de publicidad política que benefició al obregonismo, solamente." ${ }^{2}$

Dos días después de la reunión con González, y antes de que se le enjuiciara por el "caso Cejudo", el general invicto escapó gracias al apoyo de Juan Zubarán Capmany, Miguel Alessio Robles y Benjamín Hill. Se dirigió en un ferrocarril a Guerrero, ayudado por el maquinista Margarito Ramírez; allí fue recibido por Maycotte, jefe de Operaciones Militares de la región, y del gobernador Francisco Figueroa. Asimismo, los gonzalistas que debían cuidar el estado de Morelos, el general Francisco Cossío Robelo, en Cuernavaca, y el general Salvador González, en Cuautla, hicieron caso omiso a las órdenes del gobierno; por ello el subsecretario de Guerra, general Francisco Urquizo envió al general Gustavo Elizondo a la zona para tratar de perseguir a los rebeldes, pero tampoco realizó su trabajo. En cambio, los zapatistas recibieron armamento y municiones para unirse a la rebelión.

El 23 de abril de 1920 se firmó el Plan de Agua Prieta que concretaba la ruptura de Sonora con el gobierno federal y designaba como cabeza del movimiento a Adolfo de la Huerta y al general Plutarco Elías Calles como jefe militar. Precisamente, durante los últimos días de abril se concretó el pacto entre los gonzalistas de la zona y Obregón, quien de Iguala, después de dar a conocer un manifiesto en el que apoyaba el movimiento liderado por De la Huerta, se dirigió al Puente de Ixtla en donde se encontró con el general Cossío Robelo; poco después el general Elizondo también se sumó a la marejada aguaprietista. El 2 de mayo, Obregón abandonó Iguala para dirigirse en tren a la ciudad de México; en Zacatepec, Morelos, los esperaban los generales Hill, Salvador González y Genovevo de la O, entre otros

${ }^{82}$ Prieto Laurens, Cincuenta años de política..., p. 78. Las cursivas aparecen en el original. 
jefes sureños. ${ }^{83}$ Los zapatistas y gonzalistas habían cerrado el acuerdo con la causa sonorense, que fue un paso importante para la reunificación revolucionaria liderada por Álvaro Obregón.

Los días siguientes los periódicos de la capital llenaron sus páginas de especulaciones sobre el futuro del país y de las elecciones presidenciales. El mismo día que se publicó el Plan de Agua Prieta se especuló que Bonillas había abandonado su candidatura, pero pronto fue desmentido y se dio a conocer ampliamente en El Heraldo de México:

Ayer circuló con mucha insistencia, en diferentes círculos sociales de esta capital, el rumor de que el ingeniero don Ignacio Bonillas había hecho formal renuncia ante el Partido Civilista de la candidatura para ocupar la Presidencia de la república, ofrecida por el mismo partido.

Inmediatamente procuramos informarnos sobre la veracidad de la versión, quedando completamente desmentida por el licenciado Alfonso Cravioto, líder de la propaganda civilista. Por el contrario, sabemos que muy en breve saldrá el señor Ingeniero Bonillas para los Estados de Puebla y Veracruz, en viaje de propaganda, acompañado del general Federico Montes, Presidente del Partido y de connotadas personalidades. ${ }^{84}$

No obstante, era prácticamente un hecho que las elecciones no se llevarían a cabo, al menos así lo expresó el mismo diario una semana más tarde. ${ }^{85}$

¿Estrategia del periódico, de Carranza o del propio general neoleonés? El Heraldo de México comenzó una campaña que puede responder las interrogantes, y González pareció ser por unos días el intermediario para que el conflicto se solucionara y que incluso se postergaran los comicios. En El Heraldo de México se criticó la situación de guerra que imperaba en el país desde que Obregón escapó de la ciudad de México y se habían intensificado las hostilidades entre Carranza y el gobierno del estado de Sonora. Se afirmó que las candidaturas existentes desaparecerían, Bonillas y González estaban dispuestos a renunciar a sus pretensiones políticas y la de Obregón ya no tenía "razón de ser" por haberse levantado en armas contra el gobierno carrancista.

${ }^{83}$ John Womack, Zapata y la Revolución Mexicana, 2a. ed., México, Siglo XXI, 1969, p. 354-357.

${ }^{84}$ El Heraldo de México, 23 de abril de 1920, p. 1.

${ }^{85}$ Ibidem, 29 de abril de 1920, p. 1, 8. 
¿Qué ocurría en el país para que se divulgaran las supuestas alianzas entre los partidarios de González y Bonillas? Una vez consumada la fractura entre el gobernador de Sonora y el gobierno federal, los gobernadores de otros estados hicieron lo propio en sus entidades, como Pascual Ortiz Rubio en Michoacán, Enrique Estrada en Zacatecas y Carlos Greene en Tabasco, así como otros generales, entre los que se encontraban Arnulfo R. Gómez en la Huasteca al lado del general Manuel Peláez y Ángel Flores en Culiacán, Sinaloa, el 20 de abril. El gobierno intentó responder con el anuncio de que Diéguez se trasladaría a Sonora en el cañonero Guerrero para pacificar la situación y en la costa del golfo el general Cándido Aguilar formaría una columna con tropas de Puebla y Veracruz para combatir a los rebeldes, pero poco pudieron $-\mathrm{o}$ quisieron- hacer. ${ }^{86}$

Según lo publicado en El Heraldo de México, bonillistas y gonzalistas se unirían para evitar conflictos nacionales de mayor impacto, ${ }^{87}$ aunque en realidad el movimiento anticarrancista se había extendido por gran parte del país. En el mismo diario se afirmó que los "delegados de ambos candidatos hicieron un resumen de la situación del país en los órdenes social y militar" para evitar todo lo que perjudicara "a la patria" y para ello pondrían su mayor esfuerzo. Al día siguiente se anunció que todas las negociaciones entre los candidatos, González y Bonillas, habían fracasado ya que los gonzalistas "extremaron sus exigencias y las conferencias fracasaron completamente por este motivo". ${ }^{88}$ Ninguno de los dos candidatos se retiraría en la carrera por alcanzar la presidencia.

Paralela y contrariamente a lo que se aseguraba en los diarios capitalinos, el 30 de abril González desconoció definitivamente al gobierno con base en un manifiesto y se trasladó a Texcoco en compañía de Jacinto Blas Treviño y Manuel W. González. ${ }^{89}$ En el documento de ruptura definitiva con Carranza el neoleonés explicó el dilema al que se enfrentaba el país después de diez años de lucha armada debido a que, nuevamente, como en los tiempos de Porfirio Díaz cuando se "impuso" a Ramón Corral en la vicepresidencia, Carranza buscaba imponer a Bonillas, lo que significaba "la negación de los principios revolucionarios". Pese al inicio de una nueva lucha, González aseguraba que la nueva revolución sería breve y sin

\footnotetext{
${ }^{86}$ Matute, La carrera..., p. 100.

${ }^{87}$ El Heraldo de México, 29 de abril de 1920, p. 1, 8.

${ }^{88}$ Ibidem, 30 de abril de 1920, p. 1, 8.

${ }^{89}$ El Demócrata, 2 y 3 de mayo de 1920, p. 1; Matute, La carrera..., p. 116.
} 
violencia para volver lo más pronto posible a la normalidad..$^{90}$ Dos días más tarde, Francisco Cossío Robelo lanzó un manifiesto anticarrancista, por lo que el valle de México y sus alrededores quedaron en manos gonzalistas. ${ }^{91}$

El 5 de mayo, antes de abandonar la ciudad de México, Carranza publicó un documento en el que expuso los errores que, desde su punto de vista, estaban cometiendo los candidatos. Destacó la postura militarista de Obregón y sus alianzas con los diferentes grupos rebeldes del país; de González cuestionó su nula campaña electoral y el uso de sus influencias militares para sublevarse contra el gobierno cuando lo creyó pertinente. El presidente también hizo públicas las supuestas reuniones entre González y Bonillas en abril de 1920 y afirmó que ambos habían aceptado dejar de lado sus pretensiones políticas para combatir la rebelión obregonista, aunque al final González tuvo una actitud "sospechosa" y se unió a la revuelta. ${ }^{92}$ El divisionario neoleonés, como a lo largo de toda su campaña electoral, jugó fríamente todas sus cartas y esperó pacientemente el momento justo para actuar.

La situación se volvió insostenible para el gobierno de Carranza, quien decidió trasladarse con su gabinete a Veracruz tratando de emular lo realizado en noviembre de 1914 cuando la lucha contra Villa, Zapata y la Convención vivía sus primeros momentos. En Veracruz el gobernador Cándido Aguilar dio órdenes al general Guadalupe Sánchez para que defendiera al estado y le brindara seguridad al presidente, la salida por Tampico era imposible debido a que se trataba de la zona de influencia de los generales Arnulfo R. Gómez y Manuel Peláez. Finalmente el 7 de mayo Carranza partió con sus colaboradores. ${ }^{93}$ No obstante, sus planes fracasaron rápidamente, Sánchez optó por no defender al gobierno y la comitiva presidencial tuvo que emprender el viaje por la sierra poblana, en donde al llegar a Aljibes las tropas leales al gobierno, lideradas por el general Francisco Murguía, fueron prácticamente derrotadas.

¿Qué significó la estrategia de espera de González, acaso aún pensó en apoyar a Carranza? Sin duda alguna, el candidato neoleonés tuvo una actitud indecisa desde el inicio; se mantuvo vigilante, en espera ya sea de ser el elegido de última hora del presidente o de levantarse en armas. Sin embargo, a finales de abril de 1920 posiblemente buscó llegar a un acuerdo

\footnotetext{
${ }^{90}$ Pablo González, "Manifiesto”, El Demócrata, 8 de mayo de 1920, p. 1, 3-5.

${ }^{91}$ Matute, La carrera..., p. 116.

${ }^{92}$ Venustiano Carranza, “Manifiesto a la nación”, El Demócrata, 6 de mayo de 1920, p. 5.

${ }^{93}$ Idem.
} 
con Carranza y su candidato predilecto, Ignacio Bonillas. El posible nuevo pacto no se concretó y González simplemente se dejó guiar por los vientos aguaprietistas, pese a no estar completamente de acuerdo con el movimiento ni con sus líderes.

Después de la marcha del "tren dorado" que debía llevar sano y salvo al presidente hasta Veracruz, González parecía salir airoso al tomar posesión de la ciudad de México. El mismo día que Carranza emprendió su partida, los generales entraron a la capital del país al frente del llamado Ejército Liberal Revolucionario. Llegaron a Palacio Nacional y ofrecieron un discurso para calmar el descontrol social. ${ }^{94}$ Treviño hizo un llamado al ramo comercial para que continuara sus labores con normalidad:

El Ejército Liberal Revolucionario, cuya vanguardia ocupa esta plaza bajo mis órdenes directas, hace del conocimiento de los habitantes de la ciudad de México, que está dispuesto a dar toda clase de garantías, pudiendo por lo tanto, abrirse las puertas del comercio, la banca y la industria, realizando sus operaciones sin temor a que sufran prejuicio de parte de nuestras tropas.

Hago del conocimiento del comercio que no encuentro motivo justificado para el alza de los precios en las mercancías de primera necesidad y por tal motivo se procederá con toda energía contra aquellos que pretendan especular, aprovechándose de la anormal situación..$^{95}$

Se designó comandante militar provisional de la plaza de México al general brigadier Sidronio Méndez, quien debía asegurar la impartición de justicia y los servicios de vigilancia en la ciudad. No obstante, el liderazgo gonzalista al frente de la metrópoli duró poco tiempo; fue un triunfo efímero, coyuntural.

Como discípulos de Carranza, los gonzalistas entendieron que, si en 1914 se había puesto fin al periódico más importante del régimen porfirista, El Imparcial, ahora también se debía terminar con la oposición periodística que tantas trabas había puesto en su campaña durante la coyuntura electoral. Por ello una de las primeras acciones realizadas por el general Méndez fue tomar posesión de las instalaciones de El Demócrata. ${ }^{96}$ En su

${ }^{94}$ El Demócrata, 8 de mayo de 1920, p. 1; John W. F. Dulles, Ayer en México: una crónica de la revolución, 1919-1936, México, Fondo de Cultura Económica, 1977, p. 41; Alessio Robles, Historia política..., p. 237.

${ }^{95}$ El Universal, 7 de mayo de 1920, p. 1.

${ }^{96}$ El Demócrata, 14 de mayo de 1920, p. 1. 
nueva época El Demócrata se encargó de crear la imagen de Pablo González interesado en unificar a los revolucionarios y reprodujo en sus páginas los discursos expresados por el divisionario en el Palacio Nacional. El rotativo afirmó que el país estaba en "vísperas de una paz definitiva y sólida" porque las tendencias políticas dominantes, las que se habían encargado de prevenir la imposición bonillista, el "pablismo y el obregonismo", se unirían para establecer un nuevo gobierno legal. ${ }^{97}$

El 9 de mayo en medio de gente curiosa, Obregón arribó a la capital, escoltado por los generales Hill, Maycotte, Manuel García Vigil y De la O, entre otros. ${ }^{98} \mathrm{El}$ Partido Liberal Constitucionalista pidió a la población que recibiera al "futuro presidente" y lo acompañaran hasta el Hotel St. Francis en donde se hospedaría. ${ }^{99}$ González aseguró un día antes: "No me preocupa otra idea que unificar a los elementos revolucionarios, para que unas elecciones perfectas den a la patria el gobierno popular que tanto desea". ${ }^{100}$

Pocos días después del arribo de Obregón a la capital de la república, el plan del presidente Carranza fracasó - con quien había intentado entrar en negociaciones de paz desde el 14 del mismo mes el general Treviño— ${ }^{101}$ y fue asesinado en Tlaxcalantongo, Puebla, el 21 de mayo de 1920 por el pelaecista Rodolfo Herrero. La "huelga de los generales", como la llamó Luis Cabrera, se consumó; los sonorenses triunfaron bajo el Plan de Agua Prieta, y el primer gobierno emanado de la Constitución de 1917 vio su fin. ${ }^{102}$ Tres días después del magnicidio, De la Huerta fue elegido presidente interino por el Congreso para cubrir el periodo del 1o. de junio al 30 de noviembre del mismo año. ${ }^{103}$

Después de múltiples rumores sobre abandonar la carrera por la presidencia de la república, el 16 de mayo de 1920 se publicó un manifiesto redactado por el propio González. ${ }^{104}$ En el documento aseguraba haber pensado en renunciar a su candidatura desde abril de 1920 cuando "descaradamente" se había revelado el intento de imposición de Bonillas por parte del gobierno en turno y dicha idea había madurado con el paso de

\footnotetext{
${ }^{97}$ Ibidem, 9 de mayo de 1920, p. 1.

${ }^{98}$ Ibidem, 9 y 10 de mayo de 1920, p. 1.

${ }^{99}$ El Universal, 9 de mayo de 1920, p. 1.

${ }^{100}$ El Demócrata, 9 de mayo de 1920, p. 1.

${ }^{101}$ Ibidem, 14 de mayo de 1920, p. 1.

${ }^{102}$ Ibidem, 3 de mayo de 1920, p. 1.

${ }^{103}$ El Universal, 25 de mayo de 1920, p. 5.

${ }^{104}$ Ibidem, 16 de mayo de 1920, p. 3.
} 
los días. Ya que, afirmaba González, lejos de guardar ambiciones personales, abandonaba la contienda para evitar nuevas luchas en el seno del ejército una vez que la "unificación" había "quedado asegurada". Agregaba el divisionario:

Mientras el general Obregón y yo luchamos en el campo democrático, era un hecho que el ejército estaba dividido entre uno y otro. Si nuestras candidaturas vuelven a contender, la división del ejército volverá a ser inevitable. Las intenciones de todos son honradas ahora, pero la política es pasional y venenosa y no sabemos hasta donde pudiera conducirnos en el futuro, máxime cuando después del sacudimiento revolucionario efectuado, los ánimos se encuentran más propensos a exaltaciones y ardimientos. ${ }^{105}$

Casi para finalizar el excandidato presidencial afirmaba que la unión que se había logrado hasta ese momento debía subsistir y, para que ello se hiciera realidad, había tomado la decisión de abandonar sus ambiciones políticas. Además agregó unas líneas que parecían estar dirigidas a Obregón: "Debo repetir que esta resolución la he venido considerando y la tengo adoptada de tiempo atrás. Ella es irrevocable y enteramente personal, sin que se relacione ni pretenda relacionarse con actitudes de otras personas a quienes reconozco el más legítimo derecho de proceder como lo consideren conveniente". ${ }^{106}$

Antes de abandonar su breve periodo al frente de la metrópoli, el 5 de junio de 1920 González dio a conocer un amplio informe sobre sus labores políticas, militares y administrativas que llevó a cabo del 30 de abril a la fecha que firmó dicho documento. En dicho escrito éste explicaba las acciones que había llevado a cabo desde que el gobierno de Carranza había abandonado la ciudad de México, principalmente aquellas para mantener - en la medida de lo posible- el funcionamiento de las secretarías de Estado y el gobierno del Distrito Federal para dar "toda clase de garantías" a la población de la capital del país y hacer frente a todos los problemas que demandaban resolución inmediata". ${ }^{107}$

El excandidato presidencial finalmente se dirigió al norte del país, en donde aseguró que se retiraría de la vida pública. La realidad fue muy

${ }^{105}$ Excélsior, 16 de mayo de 1920, p. 1.

${ }^{106}$ Ibidem, 16 y 17 de mayo de 1920, p. 1.

107 "Informe que rinde el C. General de División Pablo González al C. presidente sustituto constitucional don Adolfo de la Huerta”, en González Miller, El centinela..., p. 599. 
distinta ya que desde julio del mismo 1920 fue acusado de secundar una rebelión contra el gobierno de Adolfo de la Huerta. Pese a existir la posibilidad de ser pasado por las armas, finalmente logró salir airoso y abandonar el territorio nacional rumbo a Estados Unidos, sitio en el que permaneció poco más de veinte años antes de regresar a su natal Nuevo León en donde murió en $1950 .{ }^{108}$

\section{Consideraciones finales}

Viejas interpretaciones han permeado y limitado el estudio de la biografía política de Pablo González, a quien suele mostrarse como un hombre poco preparado en las cuestiones militares e indeciso en los avatares políticos. ¿Por qué Pablo González no fue presidente de México? Es indudable que el divisionario no tenía el carisma ni el arraigo popular de Obregón, ni de otros caudillos revolucionarios como Villa, Zapata u Obregón, pero resulta indispensable llevar a cabo estudios más equilibrados sobre su vida o etapas específicas de la misma, como en el caso de este artículo, para ofrecer respuestas más allá de los juicios de valor.

Como alumno de Carranza, de quien Matute ha señalado que una de sus principales virtudes era su parsimonia, González se caracterizó en el inicio de su campaña presidencial por no actuar impulsivamente; todas las decisiones las tomó después de reflexionarlas por largo tiempo, y no fue impaciente aunque en ocasiones su modestia lo llevó a perder posibles seguidores. No obstante, su apego a la legalidad propició que su campaña tuviera el vigor necesario y pareciera desorientada, como lo ha señalado un autor. ${ }^{109}$ Posteriormente el neoleonés no tuvo salida y tomó las medidas necesarias para conservar su propia vida.

La Liga Democrática, poco estudiada hasta hoy, no tenía las bases políticas del obregonismo que contaba con el Partido Liberal Constitucionalista que había participado y triunfado en las elecciones presidenciales de 1917, así como en las del Congreso de la Unión, distintas gubernaturas y congresos locales, por lo que ya se encontraba bien posicionado en varios estados del país. Los diversos sectores sociales, obreros y campesinos, así como los contrarrevolucionarios y exiliados también se unieron

${ }^{108}$ Matute, La carrera..., p. 141-142.

${ }^{109}$ Cumberland, La Revolución Mexicana..., p. 364. 
a la propuesta de reconciliación impulsada por el general invicto prácticamente desde que abandonó la Secretaría de Guerra y Marina en mayo de 1917. La creación del Centro Director Obregonista en febrero de 1920 -que aglutinó a los diversos partidos, asociaciones y clubes que apoyaban a Obregón-, bajo el liderazgo de hombres más cercanos al general invicto como los generales Amado Aguirre y Plutarco Elías Calles, hizo prácticamente imposible que González fuera un contendiente serio del manco de Santa Ana del Conde desde febrero de 1920; de ahí que prefiriera pactar con él antes que romper abiertamente con el Grupo Sonora. Los miembros de la Liga Democrática eran escasos y, pese a tener gran recorrido político, llegada la lucha electoral no tenían el eco necesario para fortalecer a la por sí misma ralentizada campaña de González.

Además de la imposibilidad de realizar una alianza con los zapatistas por ser el autor intelectual del asesinato de su caudillo, resultaba complicado también llevar a cabo algo similar con el sector obrero, resentido con el divisionario neoleonés desde la forma en que el gobierno del Primer Jefe intervino en la resolución de los conflictos de 1916. Junto a lo anterior, González emprendió campañas contra villistas y felicistas entre 1917 y 1919, lo que le imposibilitaba también acercarse a esos grupos para impulsar alianzas.

A diferencia de lo publicado en los principales periódicos del país. En México Nuevo, un periódico ignorado y cuya historia se esboza en este trabajo debido a los pocos ejemplares con los que se cuenta, se mostró a un Pablo González más activo desde febrero de 1920; contrariamente a lo que la prensa obregonista aseguraba, al divisionario se le veía en mítines y reuniones en distintos puntos de la capital del país. Como buen órgano de propaganda, en el diario gonzalista se trató de "construir" la imagen de González como un personaje carismático, líder de los diversos sectores sociales y uno de los contendientes más fuertes para ocupar la presidencia. Justamente, la relación de la prensa y los procesos electorales permite comprender la compleja madeja de relaciones y redes que se tejieron y destejieron en la coyuntura de 1920, relación también poco abordada en los estudios de la tercera década del siglo xx.

Hacia abril de 1920 los gonzalistas se unieron al aguaprietismo como una de tantas facciones revolucionarias más. El gonzalismo había llegado a su fin. Con base en lo antes expuesto se visualiza la forma en que el general Pablo González Garza también tuvo una plataforma política sólida, la Liga Democrática, aunque de menor alcance que la obregonista, y un periódico, 
México Nuevo, que construyó su imagen como un líder de las masas, pero que careció de una mejor estrategia de propaganda, como en su momento lo hizo El Monitor Republicano en favor de Obregón.

\section{FUENTES}

Archivos

Fideicomiso Archivos Plutarco Elías Calles y Fernando Torreblanca, Fondo Álvaro Obregón

\section{Hemerografía}

El Demócrata (México, D. F., 1920)

Excélsior (México, D. F., 1919-1920)

El Heraldo de México (México, D. F., 1919-1920)

México Nuevo (México, D. F., enero-marzo, 1920)

El Monitor Republicano (México, D. F., 1919-1920)

El Pueblo (México, D. F., 1919)

El Universal (México, D. F., 1919-1920)

Libros, artículos y capítulos de libros

Alessio Robles, Miguel, Historia política de la Revolución Mexicana, México, Botas, 1946.

Memorias, 4 v., México, Instituto Nacional de Estudios Históricos de las Revoluciones de México/Gobierno del Estado de Coahuila, 2010.

Barragán Rodríguez, Juan, Historia del Ejército y de la Revolución Constitucionalista, México, Instituto Nacional de Estudios Históricos de la Revolución Mexicana, 1986.

Betancourt Cid, Carlos (comp.), Los hombres de la Soberana Convención Revolucionaria, México, Instituto Nacional de Estudios Históricos de las Revoluciones de México/Secretaría de Educación Pública/Congreso del Estado de Aguascalientes-LXII/Universidad Autónoma de Aguascalientes, 2014. 
Blasco Ibáñez, Vicente, El militarismo mejicano. Estudios publicados en los principales diarios de los Estados Unidos, Valencia, Prometeo, 1920.

Воввіо, Norberto у Nicola Mateucci, Diccionario de política, 2 v., México, Siglo XXI, 1982.

Burkholder de la Rosa, Arno, "El periódico que llegó a la vida nacional. Los primeros años del diario Excélsior (1916-1932)”, Historia Mexicana, El Colegio de México, Centro de Estudios Históricos, México, v. LVIII, n. 232, abril-junio 2009, p. 1369-1418.

CARr, Barry, El movimiento obrero y la política en México, 1910-1929, 2 v., México, Secretaría de Educación Pública, 1976.

Castro, Pedro, Álvaro Obregón. Fuego y cenizas de la Revolución Mexicana, México, Era/Consejo Nacional para la Cultura y las Artes, 2009.

Contreras, Mario, y Jesús Tamayo (comp.), Antología. México en el siglo xx, 19131920. Textos y documentos, México, Universidad Nacional Autónoma de México, Facultad de Filosofía y Letras, 1976.

Cruz García, Ricardo, Nueva Era y la prensa en el maderismo, México, Universidad Nacional Autónoma de México, Instituto de Investigaciones Históricas, 2013.

Cumberland, Charles C., La Revolución mexicana. Los años constitucionalistas, México, Fondo de Cultura Económica, 1975.

Diccionario de generales de la Revolución, México, Instituto Nacional de Estudios Históricos de las Revoluciones de México/Secretaría de la Defensa Nacional/ Secretaría de Educación Pública, 2014.

Dulles, John W. F., Ayer en México: una crónica de la revolución, 1919-1936, México, Fondo de Cultura Económica, 1977.

Echeverría A. Marquina, Javier, ¡Viva Carranza! Mis recuerdos de la Revolución, México, Marvel, 1963.

Gantús, Fausta, y Alicia Salmerón (coord.), Prensa y elecciones. Formas de hacer política en el México decimonónico, México, Instituto de Investigaciones Dr. José María Luis Mora, 2014.

, Cuando las armas hablan, los impresos luchan, la exclusión agrede..., México, Instituto de Investigaciones Dr. José María Luis Mora, 2016.

GARCiAdiego, Javier, “La prensa durante la Revolución Mexicana”, en Aurora Cano Andaluz (coord.), Las publicaciones periódicas y la historia de México, México, Universidad Nacional Autónoma de México, 1995, p. 71-88.

"Pablo González y las dificultades en el noreste", en Así fue la Revolución Mexicana, 9 v., México, Comisión Nacional para la Celebración del 175 Aniversario de la Independencia Nacional y 75 Aniversario de la Revolución Mexicana, Senado de la República/Secretaría de Educación Pública, Instituto Nacional 
de Antropología e Historia/Consejo Nacional de Fomento Educativo, Dirección General de Publicaciones y Medios, 1985, v. 4, p. 559-565.

"Los éxitos de Pablo González", en Así fue la Revolución Mexicana, 9 v., México, Comisión Nacional para la Celebración del 175 Aniversario de la Independencia Nacional y 75 Aniversario de la Revolución Mexicana, Senado de la República/Secretaría de Educación Pública, Instituto Nacional de Antropología e Historia/Consejo Nacional de Fomento Educativo, Dirección General de Publicaciones y Medios, 1985, v. 4, p. 661-665.

GonzÁlez Marín, Silvia, Prensa y poder político. La elección presidencial de 1940 en la prensa mexicana, México, Siglo XXI/Universidad Nacional Autónoma de México, Instituto de Investigaciones Bibliográficas, 2006.

GonzÁlez Miller, Pablo, El centinela fiel del Constitucionalismo. Un libro excepcional que combate 50 años de engaño, conteniendo 400 facsímiles de documentos históricos auténticos, que expresan la verdad directa y desmienten y modifican la hasta ahora falsa historia oficial de la Revolución Mexicana en la mayor parte de sus conceptos básicos, Saltillo, Textos de Cultura Historiográfica, 1971.

José Valenzuela, Georgette, La campaña presidencial de 1923-1924 en México, México, Instituto Nacional de Estudios Históricos de la Revolución Mexicana, 1985.

"La rebelión delahuertista: sus orígenes y consecuencias políticas, económicas y sociales", en Javier Garciadiego (coord.), El Ejército Mexicano. 100 años de historia, México, El Colegio de México, 2014, p. 213-270.

Matute, Álvaro, La carrera del caudillo, México, El Colegio de México, 1980 (Col. Historia de la Revolución Mexicana, 8).

Contraespionaje político y sucesión presidencial. Correspondencia de Trinidad W. Flores sobre la primera campaña electoral de Álvaro Obregón, México, Universidad Nacional Autónoma de México, Instituto de Investigaciones Históricas, 1985.

Las dificultades del nuevo Estado, México, El Colegio de México, 1995 (Col. Historia de la Revolución Mexicana, 7).

MÉndez Lara, Francisco Iván, "Salvador Alvarado y las elecciones de 1920, una candidatura olvidada”, Secuencia, n. 99, 2017, p. 129-159.

Pineda Gómez, Francisco, La guerra zapatista, 1916-1919, México, Era/Secretaría de Cultura, Instituto Nacional de Antropología e Historia, 2019.

Prieto Laurens, Jorge, Cincuenta años de política mexicana. Memorias políticas, México, Editora Mexicana de Periódicos, Libros y Revistas, 1968.

Ribera Carbó, Anna, La Casa del Obrero Mundial. Anarcosindicalismo y revolución en México, México, Instituto Nacional de Antropología e Historia, 2010. 
Ruvalcaba, Luis N., Campaña política del [...] candidato a la Presidencia de la República, 1920-1924, México, s. e., 1923.

SALmerón, Pedro, Los carrancistas. La historia nunca contada del victorioso Ejército del Noreste, México, Planeta, 2009.

Serna Rodríguez, Ana María, "Periodismo, Estado y opinión pública en los inicios de los años veinte (1919-1924)”, Secuencia, n. 68, 2007, p. 57-85.

, "Prensa y sociedad en las décadas revolucionarias (1910-1940)", Secuencia, n. 86, 2014, p. 111-149.

UlloA, Berta, La Constitución de 1917, México, El Colegio de México, 1983 (Col. Historia de la Revolución Mexicana, 6).

Woмaск, John, Zapata y la Revolución Mexicana, 2a. ed., México, Siglo XXI, 1969. 